\title{
Principal component analysis-aided statistical process optimisation (PASPO) for process improvement in industrial refineries
}

TENG, S.; HOW, B.; LEONG, W.; TEOH, J.; CHEE, A.; MOTAVASEL, R.; LAM, H.

Journal of Cleaner Production

2019, vol. 225, July 2019, pp. 359-375

ISSN: 0043-1648

DOI: https://doi.org/10.1016/j.jclepro.2019.03.272

Accepted manuscript

(C) 2019. This manuscript version is made available under the CC-BY-NC-ND 4.0 license (http://creativecommons.org/licenses/by-nc-nd/4.0/), doi:

https://doi.org/10.1016/j.jclepro.2019.03.272

Final version available from

https://www.sciencedirect.com/science/article/pii/S0959652619309825 


\section{Accepted Manuscript}

Principal component analysis-aided statistical process optimisation (PASPO) for process improvement in industrial refineries

Sin Yong Teng, Bing Shen How, Wei Dong Leong, Jun Hao Teoh, Adrian Chee Siang Cheah, Zahra Motavasel, Hon Loong Lam

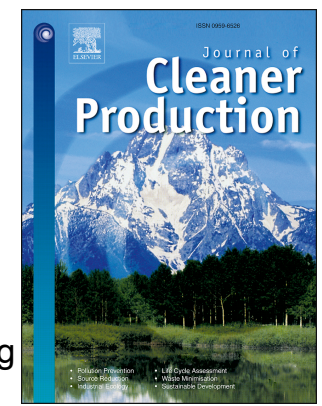

PII:

S0959-6526(19)30982-5

DOI:

https://doi.org/10.1016/j.jclepro.2019.03.272

Reference: JCLP 16276

To appear in: Journal of Cleaner Production

Received Date: 26 August 2018

Revised Date: 27 February 2019

Accepted Date: 25 March 2019

Please cite this article as: Teng SY, How BS, Leong WD, Teoh JH, Siang Cheah AC, Motavasel Z, Lam HL, Principal component analysis-aided statistical process optimisation (PASPO) for process improvement in industrial refineries, Journal of Cleaner Production (2019), doi: https://doi.org/10.1016/ j.jclepro.2019.03.272.

This is a PDF file of an unedited manuscript that has been accepted for publication. As a service to our customers we are providing this early version of the manuscript. The manuscript will undergo copyediting, typesetting, and review of the resulting proof before it is published in its final form. Please note that during the production process errors may be discovered which could affect the content, and all legal disclaimers that apply to the journal pertain. 


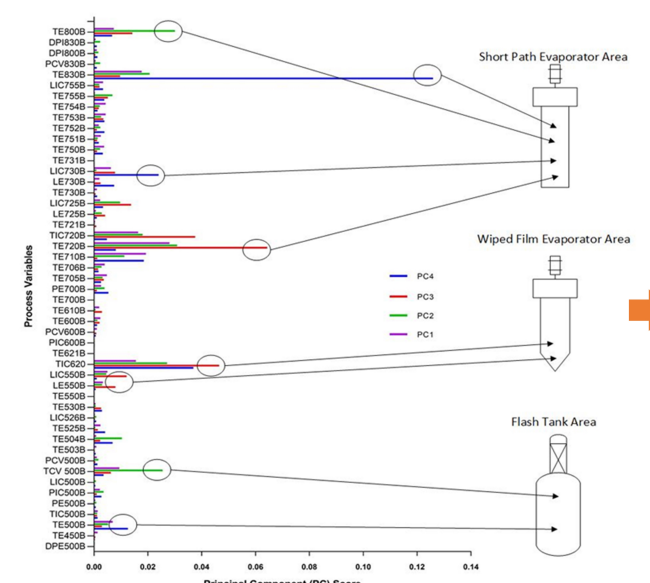

Principal Component Analysis

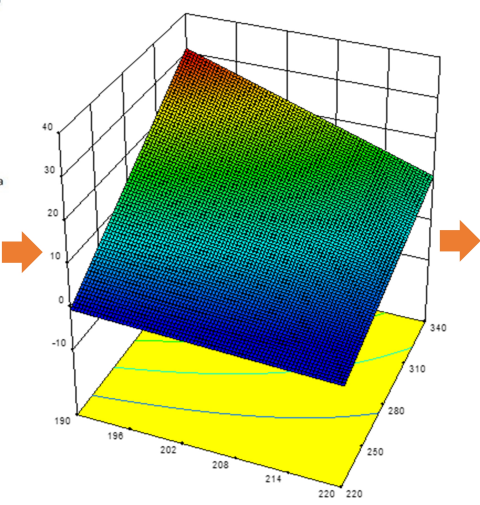

DoE Optimisation

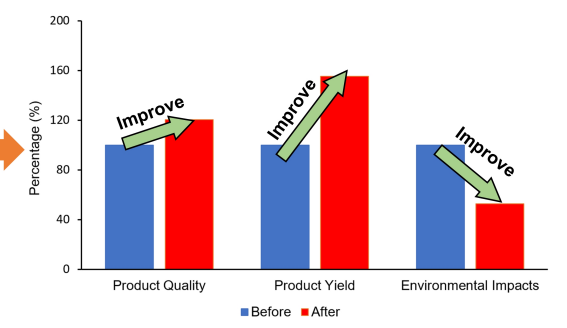

Lean and Green Improvements 


\section{Principal Component Analysis-aided Statistical Process Optimisation (PASPO) for Process Improvement in Industrial Refineries}

Sin Yong Tenga, Bing Shen How ${ }^{b}$, Wei Dong Leong ${ }^{c}$, Jun Hao Teoh ${ }^{c}$, Adrian Chee Siang Cheah ${ }^{c}$, Zahra Motavasel ${ }^{c}$, Hon Loong Lam ${ }^{c, *}$ ${ }^{a}$ Brno University of Technology, Institute of Process Engineering \& NETME Centre, Technicka 2896/2, 61669 Brno, Czech Republic

${ }^{\mathrm{b} C h e m i c a l}$ Engineering Department, Faculty of Engineering, Computing and Science, Swinburne University of Technology, Jalan Simpang Tiga, 93350 Kuching, Sarawak Malaysia.

'Department of Chemical and Environmental Engineering, University of Nottingham Malaysia Campus, Jalan Broga, 43500 Semenyih, Selangor, Malaysia.

*Corresponding author: HonLoong.Lam@nottingham.edu.my

\section{Abstract:}

Integrated refineries and industrial processing plant in the real-world always face management and design difficulties to keep the processing operation lean and green. These challenges highlight the essentiality to improving product quality and yield without compromising environmental aspects. For various process system engineering application, traditional optimisation methodologies (i.e., pure mix-integer non-linear programming) can yield very precise global optimum solutions. However, for plant-wide optimisation, the generated solutions by such methods highly rely on the accuracy of the constructed model and often require an enumerate amount of process changes to be implemented in the real world. This paper solves this issue by using a special formulation of correlation-based principal component analysis (PCA) and Design of Experiment (DoE) methodologies to serve as statistical process optimisation for industrial refineries. The contribution of this work is that it provides an efficient framework for plant-wide optimisation based on plant operational data while not compromising on environmental impacts. Fundamentally, PCA is used to prioritise statistically significant process variables based on their respective contribution scores. The variables with high contribution score are then optimised by the experiment-based optimisation methodology. By doing so, the number of experiments run for process optimisation and process changes can be reduced by efficient prioritisation. Process cycle assessment ensures that no negative environmental impact is caused by the optimisation result. As a proof of concept, this framework is implemented in a real oil re-refining plant. The overall product yield was improved by $55.25 \%$ while overall product quality improved by $20.6 \%$. Global Warming Potential (GWP) and Acidification Potential (AP) improved by $90.89 \%$ and $3.42 \%$ respectively. 
Keyword: Principal Component Analysis, Design of Experiment, Plant-wide Optimisation, Statistical Process Optimization, PASPO, Big Data Analytics

\subsection{Introduction}

Development of manufacturing plants is closely correlated with global warming, resource depletion, rising threats in food, water and energy securities and other widespread environmental risks (Wang et al., 2017). Global manufacturing environmental consequences have urged the development of cleaner and sustainable manufacturing processes (Klemes et al., 2012). The concept of sustainable development has been targeted to achieve present needs without compromising future development in the Brundtland report (WCED, 1987). Various researchers have reported that adopting the concept of green and sustainable manufacturing can lead to a significant improvement in overall performances (Lam et al., 2016). The current research paradigm has shifted to cope with the rising demand and awareness in attaining sustainable goals (Wan Alwi et al., 2014). Porter and Linde (1995) provided excellent resource conservation cases for which the "Lean and Green" strategy was adopted. The main objective of lean is to eliminate non-value-added product (Leong et al., 2018). Green, on the other hand, represents ecological sustainability which encompasses various environmental concerns, including waste generation and recycling, air, water and land pollution, energy usage and efficiency (Bhattacharya et al., 2011).

The oil and gas industry (Atanas et al., 2016), palm industry (Huda et al., 2018), and other industries have started to convert into a lean and green business model. Alsayigh (2015) performed a study on the implementation of lean and green management in oil and gas operation. Green and lean tools such as Value Stream Mapping and SWOT analysis were utilised to improve the Gulf state's oil and gas operation energy and emission (Alsayigh, 2015). Furthermore, lean tools such as Deming's Cycle can be used to optimise drill rig movement operation (Atanas et al., 2016). The implementation has successfully reduced process defects, improved team communication and developed efficient and robust process maps for operation. Amminudin et al. (2011), on the other hand, has successfully improved the propane recovery in Khurais central processing gas plant by conducting root cause analysis.

Common challenges occurring in the oil refinery industry are illiterate behaviour towards fading process performance and indiscriminate nature from the management level. As a problem statement, the abundance of operating parameters has been a formidable hurdle to process engineers in the determination of optimal operating conditions. For example, in the work of Joly et al. (2002), a case study of oil refinery optimisation 
requires 912 discrete variables and 5599 equations. In addition, many industry players tend to increase production capacity due to surges in market demand without careful and in-depth analysis of the equipment's capability and efficiency (Halvorsen et al., 2012). Inevitably, operating conditions deviates from optimal, process efficiency declines, and environmental performances are subpar coupling with deteriorating product quality.

The statistical approach is one of the simple yet effective ways to address all the mentioned issues. Notably, Design of Experiments (DoE) was first invented by Fisher (1935). The underlying principle is simply such that a sequence of test whereby intentional adjustment is made towards process variables and responses from the process are measured (Fisher, 1935). It can measure all correlations between process variables and responses by varying them simultaneously instead of individually. The process variables and responses are fitted in a mathematical model that used to effectively accelerate the optimisation (Toyota et al., 2017). DoE can also generate a predictive model for a great number of variables with a minimum experimental run (Gunst and Mason, 2009). Nevertheless, it is not practical for a complex problem which contains an extensive number of variables. In such problems, the required resources demand and computational time will increase exponentially with the increasing number of variables within the problem boundary (Telford, 2007). This weakness has become apparent when DoE is being applied in problems related to Big Data (Drovandi et al., 2017). With growing needs for Big Data analytics in industries including chemicals, energy, semiconductors, pharmaceuticals and food (Chiang et al., 2017), DoE becomes impracticable.

Fortunately, it is possible to prioritise the number of variables within a problem boundary through a multivariate statistical approach, called Principal Component Analysis (PCA). In brief, Hostelling (1933) formalised the novel instantiation of PCA. PCA is a well-known multivariate analysis method conducted to identify the principal components between variables that are interrelated and thereby reducing complicated data sets to smaller dimensions (Shlens, 2014). To-date, PCA has been broadly implemented in various research fields. Particularly for 3D imaging technology and machine learning algorithms which needs to deal with an enormous amount of data. For instance, Aida et al. (2017) have successfully improved the quality of images obtained from micro X-ray fluorescence analysis by performing PCA to improve the standard deviation of intensities peak. Ning and You (2018) reported that integrating PCA with kernel smoothing methods in the application of machine learning and data analysis for decision making has effectively 
reduced computational load and efficiency. Some other reported PCA applications are tabulated in Table 1 . Despite the natures of these works being different, the motives for using PCA are certainly identical (i.e., to reduce the dimensionality of the research problem without losing too much information).

Table 1: A list of related PCA applications

\begin{tabular}{ll}
\hline PCA Application & Authors \\
\hline $\begin{array}{l}\text { Total energy efficiency assessment and } \\
\text { optimization in manufacturing sectors }\end{array}$ & Azadeh et al. (2007) \\
$\begin{array}{l}\text { Effective assessment of water quality network } \\
\text { Multi-mode plant-wide process monitoring }\end{array}$ & Ou et al. (2012) \\
$\begin{array}{l}\text { scheme for complex chemical industries } \\
\text { Chiller sensor fault detection }\end{array}$ & Hu et al. (2016) \\
$\begin{array}{l}\text { Dynamic response of commodity markets } \\
\text { Plant-wide process monitoring with minimal }\end{array}$ & Nobi et al. (2017) \\
$\begin{array}{l}\text { redundancy maximal relevance } \\
\text { Fault detectability analysis in nuclear power }\end{array}$ & Li et al. (2018) \\
plant & How and Lam (2018a) \\
$\begin{array}{l}\text { Biomass supply chain optimisation } \\
\text { Biomass supply chain debottlenecking }\end{array}$ & How and Lam (2018b) \\
\hline
\end{tabular}

Plant-wide optimisation is often carried out using mathematical programming. Notable works related were reviewed by Klemes and Kravanja (2013), where pinch analysis and mathematical programming were used for process integration and optimisation. Furthermore, Klemes et al. (1997) also proposed a Total Site targeting and design methodology to optimise fuel, power and carbon dioxide in processing plants. For these applications, Cucek et al. (2012) have highlighted the importance of footprint analysis tools for monitoring impacts on sustainability. The idea of integrating PCA and DoE which was initially proposed by Bratchell (1989) has been carried out in a few research works. For instance, Zhang et al. (2008) focused on the utility of PCA and DoE on dynamic systems. The work aimed to optimise the control performance of a yeast fermentation reactor model by using this hybrid framework. The combination of PCA and DoE has also been used to optimise chemical reactions. Murray and Forfar (2017) have used this hybrid method for solvent and ligand selection of three different chemical reactions. In their work, the DoE factors required for optimisation was reduced from 35 to 
19 factors, which also reduced the number of experiments from 51.2 million to 6400. Furthermore, PCA and DoE have been utilised for the optimisation of a turning unit in the works of Madhavi et al. (2017). In which, the operating conditions of a single turning unit are optimised to give optimal product hardness and surface roughness.

All the reviewed works are admirable, however, none of them has tested the capability and applicability of the proposed method with the validation in a real chemical plant for plant-wide optimisation. This paper implements a novel usage of PCA and DOE that is formulated specifically for plant-wide optimization, called the Principal Component Analysis-aided Statistical Process Optimisation (PASPO). The novel PASPO framework reduces the dimensionality of the plant-wide optimization by screening computed correlation-based principal components while decoupling and recombining the principal components into process variables for critical variable selection. This paper also demonstrates the effectiveness of the PASPO framework by using an actual industrial processing plant as a case study. The PASPO framework is aimed to reduce analysis time and cost, minimise process changes required for a relatively good benefit while making plant-wide optimisation more data-oriented (instead of modeloriented). Furthermore, environmental impact analysis is carried out to study the environmental performance of the process. To achieve this, a performance indicator known as Process Cycle Assessment (a simplification of Life Cycle Analysis (LCA) to target process systems) is developed to allow instant and effortless assessment of environmental performance.

\subsection{Methodology}

The proposed PASPO framework started off with performing correlational PCA on collected data to obtain the principal components which would add up and capture more than $90 \%$ of the variance. These principal components are then decoupled into individual process variables and recombined as contribution scores. Using different coverage of contribution scores, DoE is executed on the statistically significant variables to generate a regression model in Design Expert software. Due to the complexity of the data, the regression model is very high in mathematical dimensions. Hence the best method to visualise such models is by plotting multiple three-dimensional response surface diagram of significant relations. The regression model is then numerically optimised by maximizing product yields and quality responses. It is utilised to establish a combination of optimal operating conditions whilst 
ensuring that product quality meets the requirement and environmental performance is improved (see Figure 1). The optimal operating conditions can then be plotted in a solution diagram to show its desirability and its relativeness with the high and low limits. The newly established optimum operating conditions are tested out by Process Cycle Assessment to further analyse the environmental performances.

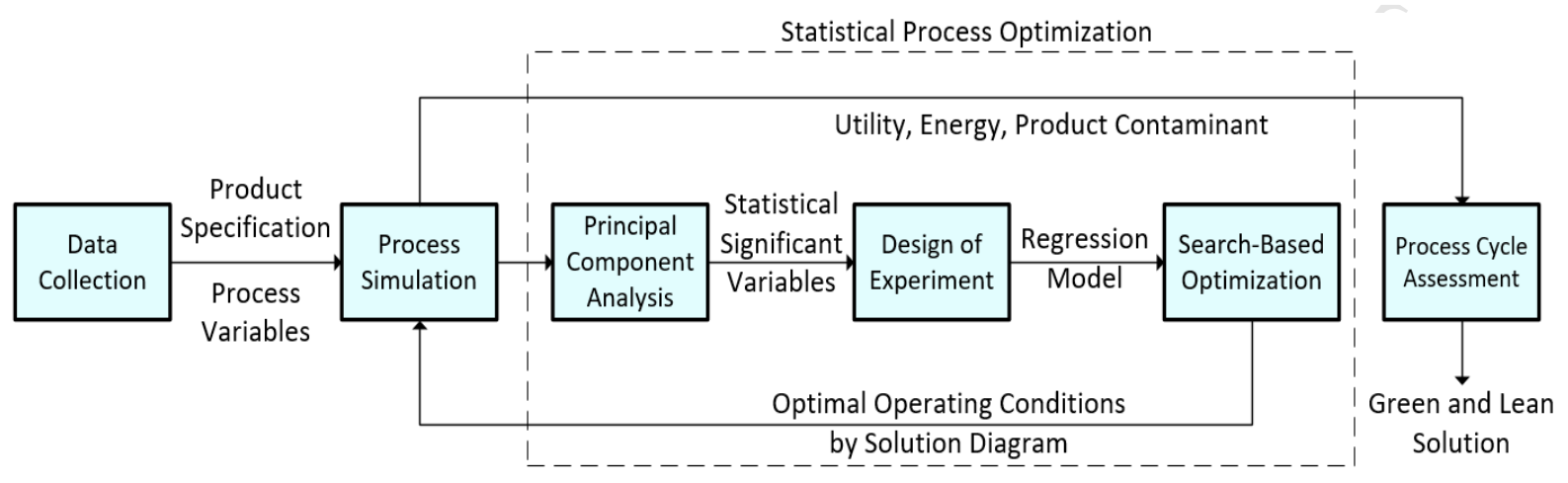

Figure 1: Overall proposed methodology for $P C A$-aided statistical process optimisation (PASPO)

The overall strategies are as below:

1. Analyse the process and plan data collection strategy

2. Data is collected for all unit operations such as operating conditions, equipment capacity and safety limits

3. The process is modelled using appropriate process simulation tool (Aspen HYSYS)

4. PCA is performed to reduce the dimensions of data

5. DoE is performed to generate a regression model

6. The regression model is used to plot a surface response curve

7. Surface response plots are utilised to visualise the regression model and study the relations between process variables.

8. Numerical optimisation is used to find an optimal operating condition that would maximise yields and quality.

9. Plot solution graph to show desirability of solution and relativeness to process limits. 
10. Optimised operating conditions is inputted into the simulated process model in step 3

11. Product quality before and after statistical optimisation are compared

12. Process Cycle Assessment is performed to evaluate the environmental performance of the process (before and after statistical process optimisation)

The detailed methodology for each strategy is demonstrated based on the Pentas Flora case study (introduced in Section 2.0) in the subsections below.

\subsection{Case Study}

The paper focuses on addressing the optimisation problem in a waste oil re-refinery plant. In general, a waste oil re-refinery plant is a refinery plant which aims to recover the quality of the used oil. In this work, a real industrial case study from Pentas Flora Sdn. Bhd. is applied to show the effectiveness of the proposed method. Firstly, the waste oil is collected from Peninsular, Malaysia and sent into a series of pretreatment facilities, i.e., flash tank dehydration unit remove moisture and light hydrocarbons from waste oil. The remaining oil is then fed into a vacuum wiped film evaporator (WFE) which has high efficiency and minimal production degradation for further processing. From there, oil is separated into light lube oil (WFE product) and heavy oil. Following is vacuum short path evaporator (SPE) that further separates the heavy oil into asphalts and medium lube oil (SPE product) which is the main product of this waste oil refinery process. Figure 2 demonstrates the overall process flow in Pentas Flora Sdn. Bhd. To achieve higher lean and green attainments, a lean and green optimisation framework is therefore presented.

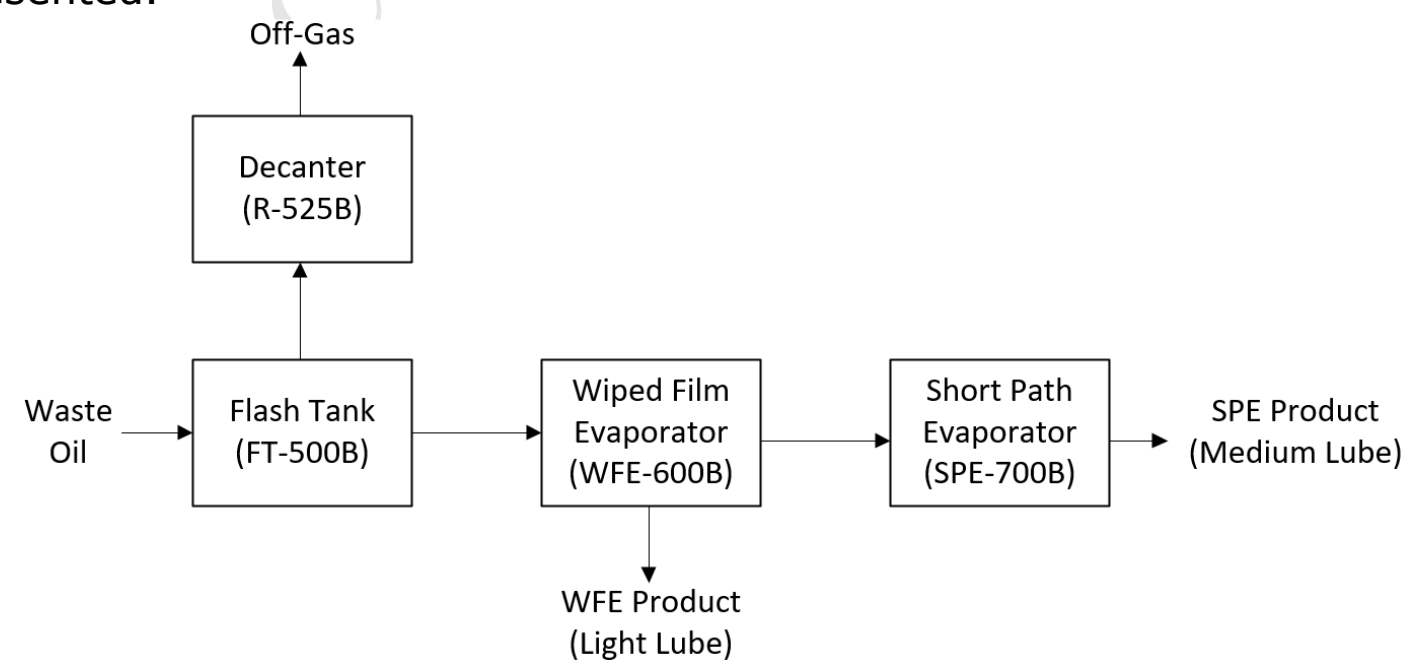


Figure 2: Simplified block flow diagram of oil re-refining case study

\subsection{Data Collection}

Data of the process is collected systematically to ensure all the potential correlations between the operating conditions and the responses are captured by the model. Therefore, this section presents the data collection step of this work. There are two sections of data collection, i.e., operating conditions and product specifications.

The steady-state operating conditions of all equipment in the process (e.g. temperature, pressure and flowrate) were recorded for 120 minutes with 5 minutes' interval. Step-changes are introduced towards the process to determine the significances of all operating parameters by calculating their covariance within the PCA study (see Table 2). Likewise, the operating conditions of all equipment are extracted after the introduction of step-changes for a time span of 2 hours with 5 minutes' interval.

Table 2: Step-changes introduced into the process for data collection

\begin{tabular}{ccccc}
\hline $\begin{array}{c}\text { Step } \\
\text { Change } \\
\text { Variable }\end{array}$ & Location & Deviation & $\begin{array}{c}\text { Study } \\
\text { Duration } \\
\text { (minutes) }\end{array}$ & $\begin{array}{c}\text { Data } \\
\text { Interval } \\
\text { (minutes) }\end{array}$ \\
\hline No change & $\begin{array}{c}\text { Full process in } \\
\text { steady-state }\end{array}$ & - & 120 & 5 \\
Temperature & $\begin{array}{c}\text { Bottom } \\
\text { temperature } \\
\text { (TIC500B) of } \\
\text { Flash tank } \\
\text { Flowrate }\end{array}$ & $\begin{array}{c}\text { Increase by } \\
5^{\circ} \mathrm{C}\end{array}$ & 120 & 5 \\
& $\begin{array}{c}\text { Waste oil feed } \\
\text { flowrate } \\
\text { (FIC450B) }\end{array}$ & $\begin{array}{c}\text { Increase by } \\
5 \mathrm{~m}^{3} / \mathrm{h}\end{array}$ & 120 & 5 \\
\hline
\end{tabular}

Oil samples were collected at waste oil feed, post flash tank product, WFE product, SPE product and asphalt during steady-state operation and two hours after step-changes were introduced. Followed by a series of lab tests in Pentas Flora Sdn. Bhd. which are Malaysian Standard Accredited 
to determine the properties of oil with appropriate standards and equipment as shown in Table 3.

Table 3: Lab test, codes and equipment

\begin{tabular}{|c|c|c|}
\hline Properties & $\begin{array}{l}\text { ASTM } \\
\text { Code }\end{array}$ & Lab Equipment \\
\hline Sulphur Content & $\begin{array}{l}\text { ASTM } \\
\text { D4294 }\end{array}$ & X-ray fluorescence spe \\
\hline Specific Gravity & $\begin{array}{c}\text { ASTM } \\
\text { D1298 }\end{array}$ & Hydrometer \\
\hline Moisture Content & $\begin{array}{l}\text { ASTM } \\
\text { D6304 }\end{array}$ & Coulometric Karl Fisher \\
\hline Flash point & ASTM D93 & Pernsky Marten Close Cup Flash Point \\
\hline Viscosity & $\begin{array}{l}\text { ASTM } \\
\text { D4684 }\end{array}$ & Mini-rotary Viscometer (MRV) \\
\hline $\begin{array}{l}\text { Boiling Point } \\
\text { Range }\end{array}$ & $\begin{array}{l}\text { ASTM } \\
\text { D2887 }\end{array}$ & $\begin{array}{l}\text { Gas Chromatography-Mass Spectroscopy } \\
\text { (GCMS) }\end{array}$ \\
\hline Molecular Weight & $\begin{array}{c}\text { ASTM } \\
\text { D1481 }\end{array}$ & Pycnometer \\
\hline
\end{tabular}

\subsection{Process Simulation}

Process simulation is carried out using HYSYS V8.8. The fluid package chosen is Sour Peng-Robinson (Sour PR) as it provides a good estimation for hydrocarbons and process consisting of hydrogen sulphide $\left(\mathrm{H}_{2} \mathrm{~S}\right)$ contaminant (Aspen Process Engineering Webinar, 2006). The waste oil feed is then modelled using an oil blend function, while its accuracy is further enhanced by incorporating bulk properties of waste oil and boiling point range (BPR) identified from lab testing as shown in Table 4.

Table 4: Bulk Properties and boiling point range of waste feed oil

Oil Sample Feed oil

Density $\left(\mathrm{kg} / \mathrm{m}^{3}\right)$

877.10 
Moisture content ( $\% \mathrm{w} / \mathrm{w})$

Sulphur content (ppm)

4719.70

Boiling point range

Initial Boiling Point (IBP)

$133^{\circ} \mathrm{C}$

$10 \%$ Vol.

$141^{\circ} \mathrm{C}$

$20 \%$ Vol.

$182^{\circ} \mathrm{C}$

$30 \%$ Vol.

$236^{\circ} \mathrm{C}$

$40 \%$ Vol.

$286^{\circ} \mathrm{C}$

$50 \%$ Vol.

$326^{\circ} \mathrm{C}$

$60 \%$ Vol.

$353^{\circ} \mathrm{C}$

$70 \%$ Vol.

$373^{\circ} \mathrm{C}$

$80 \%$ Vol.

$399^{\circ} \mathrm{C}$

$90 \%$ Vol.

$450^{\circ} \mathrm{C}$

Final Boiling Point (FBP)

$546^{\circ} \mathrm{C}$

Subsequently, a simulation process flow sheet is generated as shown in Figure 3. The robustness of the model is tested by comparing the simulated and actual quality of WFE and SPE product (see Table 5). Note that the viscosity of asphalt is not considered in the robustness test due to technical constraint (i.e., its viscosity exceeds the measuring limit of the viscometer in the lab). Evidently, the results show the deviations between simulated and actual data are less than $10 \%$. In other words, this indicates that the developed model is capable to provide accurate results as compared to the real scenario. 


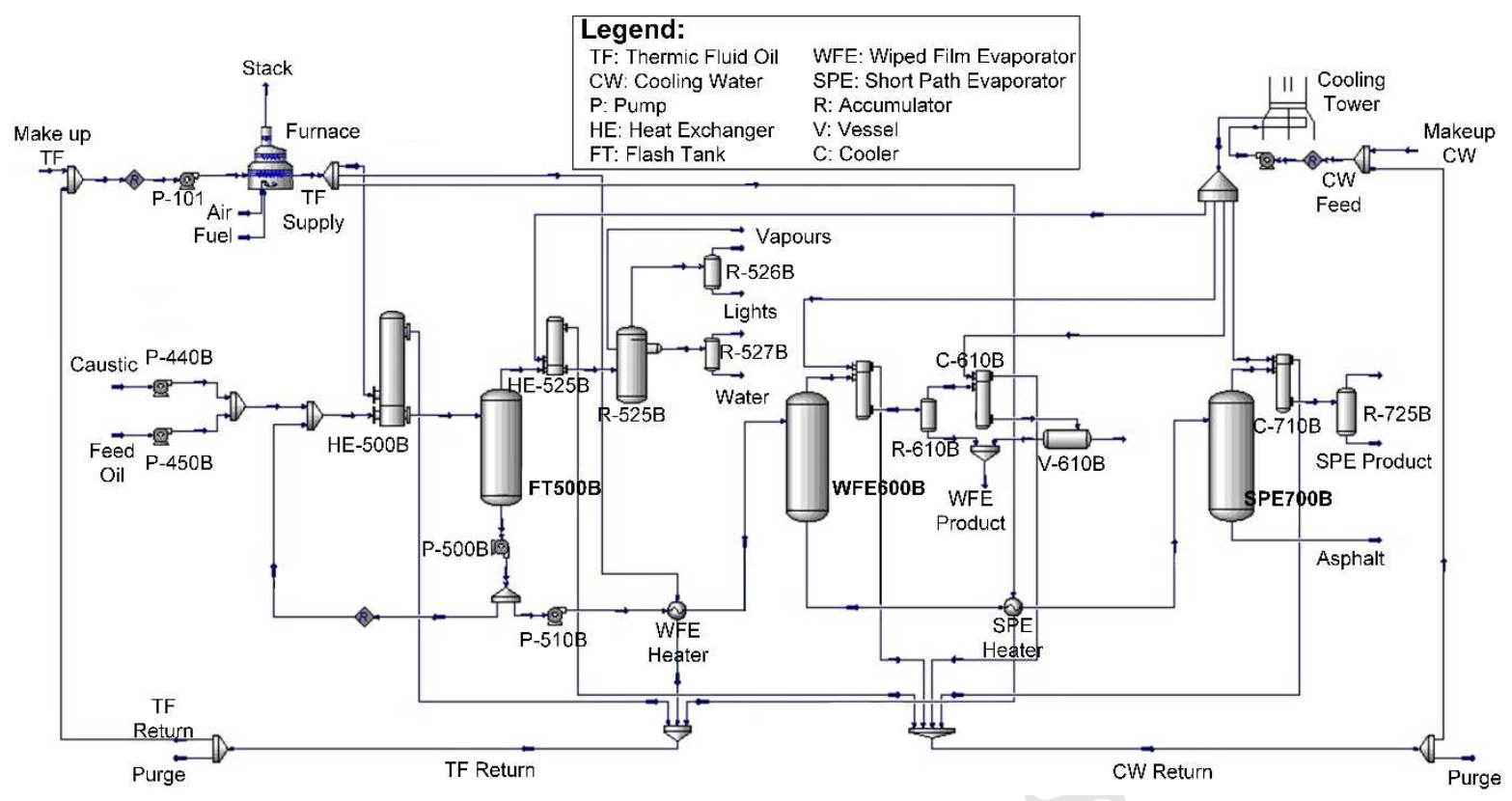

Figure 3: Simulation process flow diagram (main processing units in bold)

Table 5: Comparison between simulated and actual product specification

\begin{tabular}{ccccccc}
\hline $\begin{array}{c}\text { Oil } \\
\text { Product }\end{array}$ & \multicolumn{2}{c}{ Kinematic Viscosity (cSt) } & \multicolumn{3}{c}{ Density $\left(\mathbf{k g} / \mathbf{m}^{\mathbf{3}}\right)$} \\
\cline { 2 - 7 } & Simulated & Actual & $\begin{array}{c}\text { Deviation } \\
\mathbf{( \% )}\end{array}$ & Simulated & $\begin{array}{c}\text { Actual } \\
\text { Deviation } \\
(\%)\end{array}$ \\
\hline $\begin{array}{c}\text { WFE } \\
\text { Product } \\
\text { SPE }\end{array}$ & 16.82 & 15.37 & 9.43 & 891.5 & 848.7 & 5.04 \\
$\begin{array}{c}\text { Product } \\
\text { Asphalt }\end{array}$ & 33.49 & 31.81 & 5.28 & 892.1 & 854.8 & 4.36 \\
\hline
\end{tabular}

By doing a paired t-test on the simulated and actual data, the two-tailed $p$-value is $0.1384(t=1.8473)$. This shows that by conventional criteria, the difference between the simulated and actual data is not statistically significant (Detailed paired t-test analysis in Appendix Table 16).

\subsection{Statistical Process Optimisation}

The aim of the statistical process optimisation is to find the optimum operating conditions for the entire process. However, most of the variables are insignificant towards product quality. Thus, it is unnecessary 
to include these parameters in the optimisation model. To address this issue, the PASPO framework which integrates PCA and DoE methodologies is proposed. The conceptual idea of this hybrid framework is illustrated in Figure 4. Initially, PCA is conducted to prioritise the variables based on their respective contribution scores. Only those (variables) with high contribution score are considered in DoE methodology. With the aid of the PCA methodology, the required number of experimental runs is expected to be reduced. This further lead to lower use of experimental resources (e.g., raw material) and time spent (e.g., working hours). Hence, the overall cost (material cost, energy cost, operator wages, etc.) is gradually reduced.

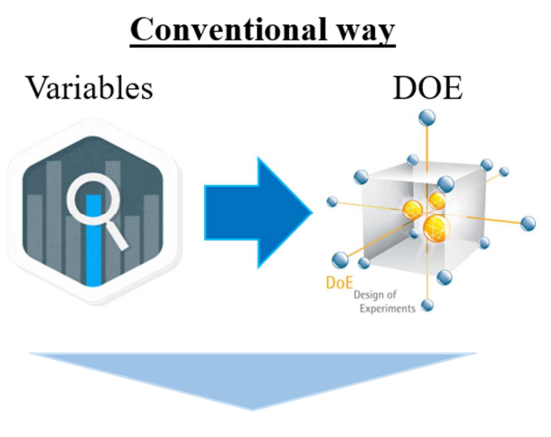

Required MORE experiment sets

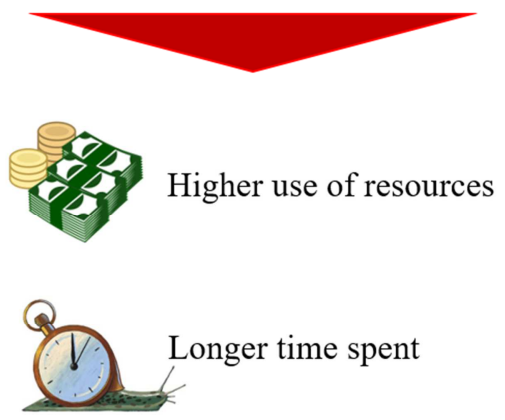

\section{Proposed way}

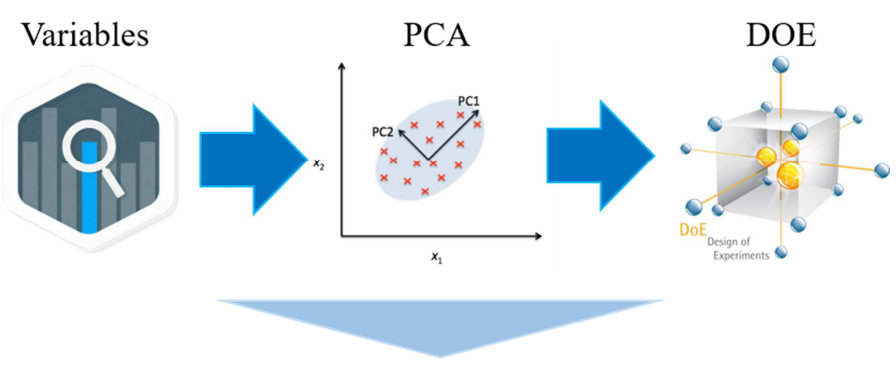

Required LESS experiment sets

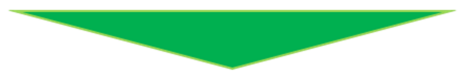

Lower use of resources

Shorter time spent

Figure 4: Conceptual idea of the PASPO framework

\subsubsection{Principal Component Analysis (PCA)}

PCA is a multivariate statistical technique capable of shrinking the dimensions of a data set consisting of innumerate correlated variables while ensuring most variations in the data set are captured (Pearson, 1901). Dimension reduction is achieved by converting the correlated variables from the original data sets into linearly uncorrelated variables, called principal components (PC). Traditionally, PCs' are determined by solving the inverse eigenvector of the covariance matrix. However, Jolliffe and Cadima (2016) discussed that traditional covariance-based PCA will give a poor representation of data when applied to combinations of variables with different units of measurement. Thus, the correlation method which involves normalisation of original data sets is performed 
instead of the covariance method (How and Lam, 2018b). The equation to evaluate the correlation between variables (Al-Sayed, 2015) is shown in Eq.(1) below.

$\operatorname{corr}\left(x_{\alpha}, x_{\beta}\right)=\frac{1}{n-1} \sum_{1}^{n}\left(\frac{x_{\alpha}-\bar{x}_{\alpha}}{\sigma_{x_{\alpha}}}\right)\left(\frac{x_{\beta}-\bar{x}_{\beta}}{\sigma_{x_{\beta}}}\right)$

In Eq.(1), $x_{\alpha}$ and $x_{\beta}$ are the comparative variables; $\bar{x}_{\alpha}$ and $\bar{x}_{\beta}$ are the average values of the corresponding variables; while $\sigma_{x_{\alpha}}$ and $\sigma_{x_{\beta}}$ are the standard deviations of the corresponding variables, and $\mathrm{n}$ is the number of variable sets. The PC is evaluated from the correlational matrix, $A$, by solving an eigenvector-eigenvalue problem, as shown in Eq.(2). The first PC (or PC1) is responsible for the majority of variance in the data, followed by second PC (PC2) and so forth.

$A v=\lambda v$

Where $A$ refers to the correlation matrix, $v$ refers to the eigenvector representing the regression coefficient of the principal components, while $\boldsymbol{\lambda}$ refers to the eigenvalue which represents process variance (Shlens, 2014). Since the variables are multivariate and direct compiling the variables into the matrix will result in a less accurate model due to weight disproportion. A normalisation of process variables is required as shown in Eq.(3) below.

$x^{\text {normalized }}=\frac{x-\bar{x}}{\sigma_{x}}$

To determine the numbers of PC included, the scree plot method with a heuristic minimum cumulative variance of $90 \%$ is used (Jackson, 1993). This is to ensure that the captured information is significant and data loss is acceptable (Rea and Rea, 2016).

Cum. Var $_{k} \geq 90 \%$

Next, the dimensions the multi-variable process inputs can be expressed as PC and be assessed using a scoring method (How and Lam, 2018b). The equation is shown in Eq. (5), where $X$ refers to the normalised process variable matrix.

PC Score $=X v$

In this work, the contribution of each variable is evaluated using an absolute method. 
Contribution Score $e_{b, z}=\frac{\left|e_{b, z}\right|}{\sum_{b}\left|e_{b, z}\right|} \quad \forall b \in B, \quad \forall z \in Z$

To select critical variables as a representation of the full information, the contribution scores for each variable are sorted from large contribution to low contribution to plot a second scree plot. The cumulative contribution score is used as an indication for consideration of process variables for optimisation.

\subsubsection{Design of Experiment (DoE)}

The statistical significant process variables obtained from PCA in Section 3.3.1 are the input variables for the experiments, also known as factors, whereas the results from the experiments are recognised as responses. Subsequently, the predictive model is generated based on the changes in factors and responses from the experiments by regression analysis (Fisher, 1935). Response surface methodology (RSM) is used to generate multiple surface response plots which are used for the latter optimisation. A full factorial methodology is adopted for this framework, as the model includes complete information on the process data (Collins et al., 2009) for optimisation. Due to the inherent nature of process systems being highly complex (McKay et al., 1997), this work considers up to $4^{\text {th }}$ order of interaction factor. Subsequently, an automatic selection algorithm with $\mathrm{p}$-value as the criterion is used to remove terms that are detrimental (Anderson, 2018).

The multi-objective optimisation technique used is a two-step optimisation coupled with the desirability function. The desirability function approach is to convert each surface response into a desirability score $d_{i}$ with a range of 0 to 1 (Derringer and Suich, 1980). The overall desirability can be expressed as the following, where $\mathrm{m}$ is the total number of responses.

$D=\left(d_{1} d_{2} \cdots d_{m}\right)^{1 / m}$

The individual desirability function for a response, $y$ with a maximum requirement is shown in Eq. (8) below.

$d=\left\{\begin{array}{cc}0 & y<T \\ \left(\frac{y-L}{T-L}\right)^{r} & T \leq y \leq U \\ 1 & y>U\end{array}\right.$

For a response targeting minimum value, the equation will be as the following. 


$$
d=\left\{\begin{array}{cc}
1 & y<T \\
\left(\frac{U-y}{U-T}\right)^{r} & T \leq y \leq U \\
0 & y>U
\end{array}\right.
$$

For the above equations, $L$ and $U$ are the lower and upper limits respectively; $r$ is the weight of the response. Setting $r>1$ prioritises the corresponding response while choosing $0<r<1$ makes the response less important. Commonly, $r$ is set to be one of the five standard levels as shown in Table 6 below (Kraber, 2009).

Table 6: Importance level and $r$ value of desirability function

\begin{tabular}{cccccc}
$\begin{array}{c}\text { Importance } \\
\text { Level }\end{array}$ & $\mathbf{1}$ & $\mathbf{2}$ & $\mathbf{3}$ & $\mathbf{4}$ & $\mathbf{5}$ \\
\hline Pulses & + & ++ & +++ & ++++ & +++++ \\
\hline $\boldsymbol{r}$ value & $10^{-1}$ & $10^{-0.5}$ & $10^{0}$ & $10^{0.5}$ & $10^{1}$ \\
\hline
\end{tabular}

In this work, the importance level of each objective is prescribed by managerial decisions after evaluating market economics and product requirements. The pulses for importance level are presented in Table 7.

Table 7: Pulses for the importance of objectives

\begin{tabular}{ccc}
\hline Properties & SPE Product & WFE Product \\
\hline Yield & +++++ & +++ \\
\hline Quality & +++ & +++ \\
\hline
\end{tabular}

Based on processing requirements, product yield is drastically more important than quality. Hence, a two-step optimisation method is applied to the desirability function for yield and quality sequentially as shown below.
Step 1: $\quad$ Max Dyield
s.t. $T_{k} \leq y_{\text {quality, } k} \leq U_{k}$
$\forall k \in K$
Step 2: Max $D_{\text {quality }}$
s.t. $T_{j} \leq y_{\text {yield, } j} \leq U_{j}$
$\forall j \in J$

In addition, factors should be manipulated within minima and maxima boundary conditions based on equipment capacities and safety limits for the desired responses. Lastly, product quality is compared before and after DoE is performed.

\subsection{Process Cycle Assessment}

Utilities, energy and equipment performance are recorded prior to and after statistical process optimisation. Impact category is chosen based on the presence of indicators in the process and similarly for the characterisation model. Lastly, the scores for the selected impact category before and after statistical process optimisation are compared. 
Process Cycle Assessment evaluates the process based on impact categories which are considered in LCA (WBCSD Chemicals, 2013). They include global warming potential (GWP) and acidification potential (AP), which are evaluated by the following equation:

$$
\begin{aligned}
& G W P=\sum_{j=1}^{\text {Stream }} M_{\text {emission }, j} \sum_{k=1}^{\text {Component }} x_{j, k} \psi_{G W P, k} \\
& A P=\sum_{j=1}^{\text {Stream }} M_{\text {emission }, j} \sum_{k=1}^{\text {Component }} x_{j, k} \psi_{A P, k}
\end{aligned}
$$

The assessment mainly considers mass flowrate of emission stream which is denoted by $M_{\text {emission, } j}$ for stream $j$. Mass fraction of contaminant component $k$ in stream $j$ is expressed as $x_{j, k}$, while the specific potential environmental impact is expressed as $\psi$. Moreover, statistical process optimisation only considers the operating conditions of the process thus, Process Cycle Assessment only assesses the performance of the equipment and the final product.

\subsection{Results}

Large sets of processing data are collected from the Supervisory Control and Data Acquisition (SCADA) system of the oil re-refinery plant which enabled the effective use of principal component analysis and design of experiments. The validated process simulation model is also used to assist the design of experiments and for the case of $99 \%$ coverage score benchmark in Section 4.3. The following sections cover the detailed result of the principal component analysis, design and analysis of experiments, optimisation results of different coverage score and process cycle assessment.

\subsection{Principal Component Analysis}

Using the computed principal component (PC) as discussed in section 3.3.1, the scree plot can be generated. The PCs are sorted from the highest eigenvalue to the lowest, while the cumulative eigenvalue (also cumulative variance) is plotted. 


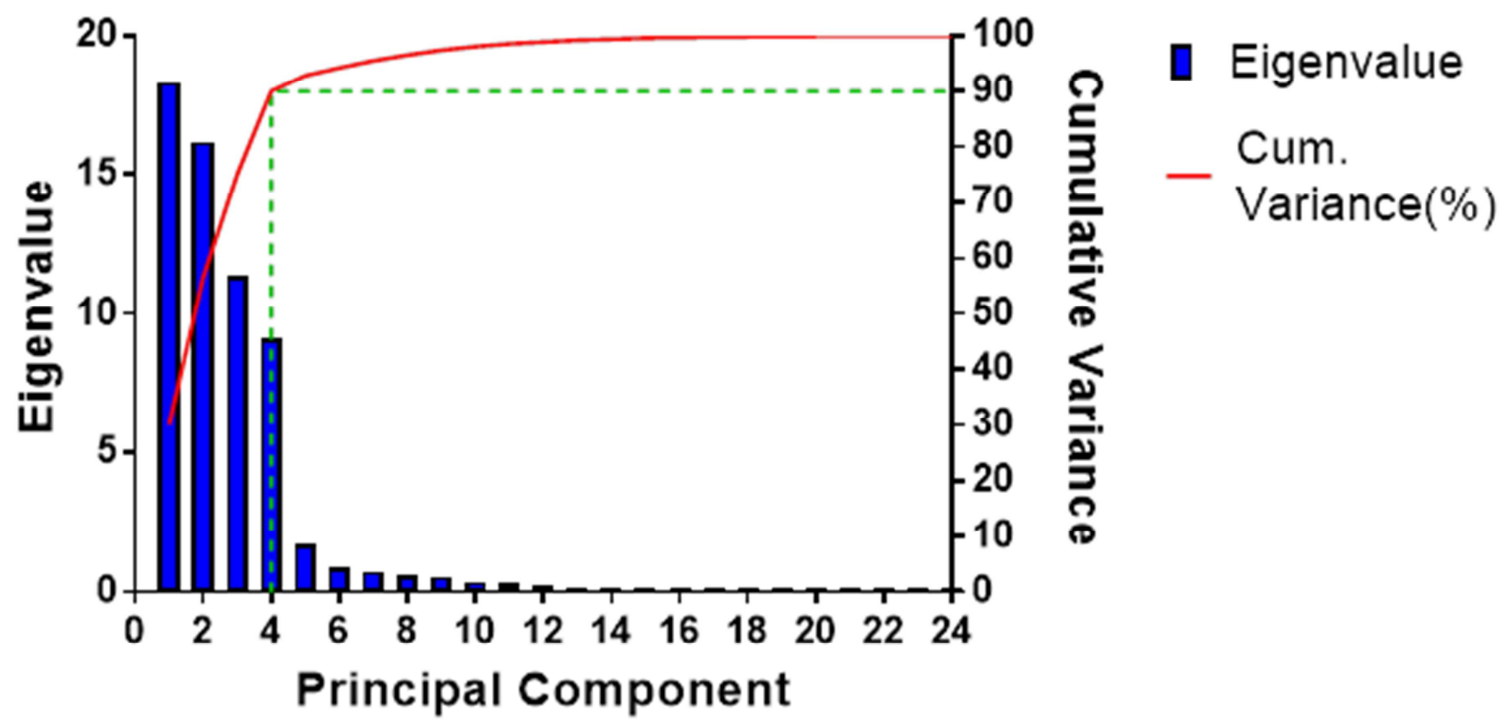

Figure 5: Scree plot of principal component

From Figure 5, there is an obvious eigenvalue drop in between the fourth PC and the fifth PC, this is commonly referred to as the "knee point". This shows that considering the first four PC is representative of the full information, while further including extra PC gives less significant results. Additionally, having four PC also satisfies the criteria of $90 \%$ minimum cumulative variance. Therefore, it is determined that four PCs will be satisfactory for this work. Subsequently, the most significant four PCs are decoupled back into process variables that contribute to them and are plotted in Figure 6. 


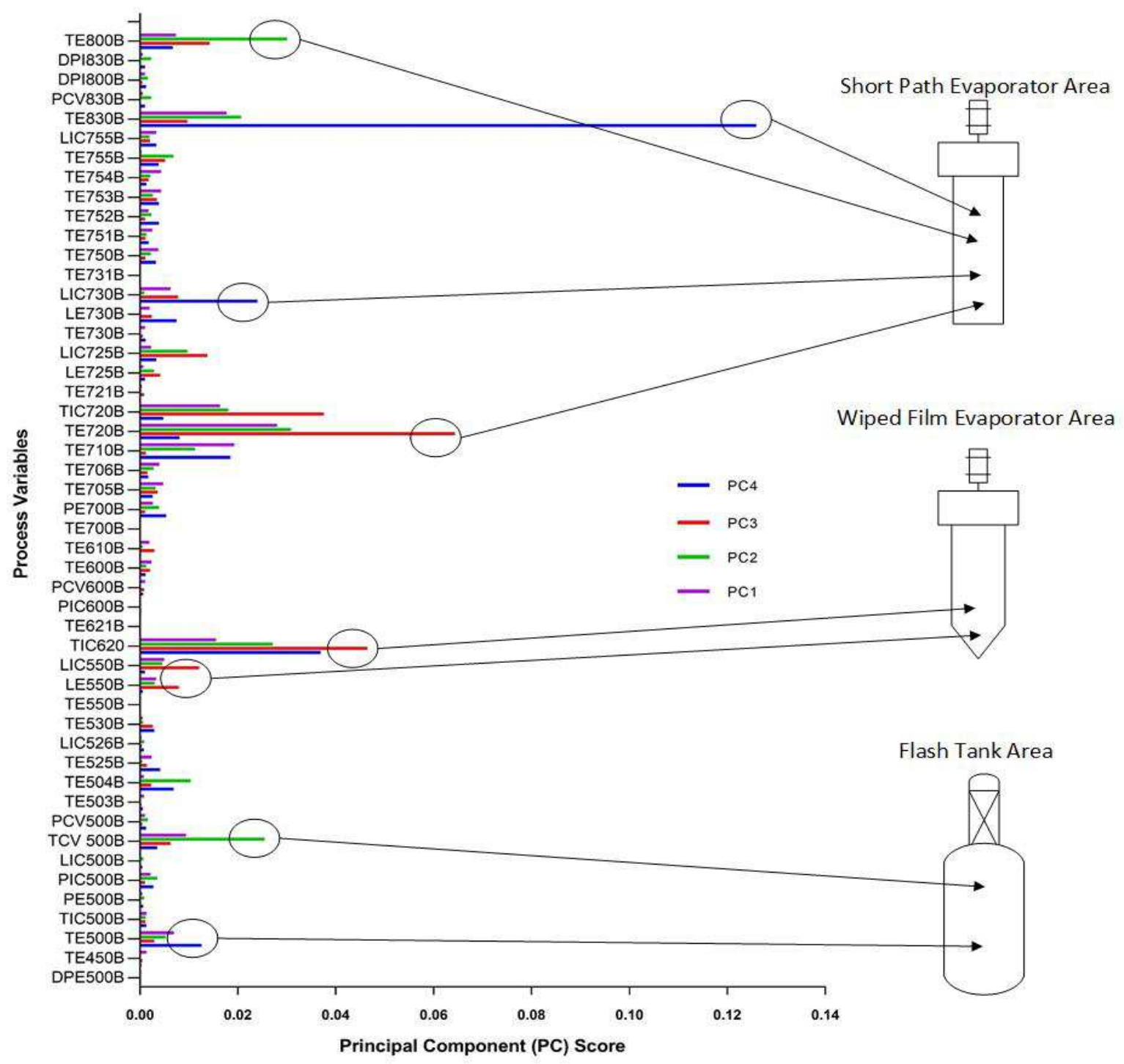

Figure 6: Contribution of Process Variables on Principal Components

Having the critical PC decoupled into process variables, some highly significant peaks are observed to highly contribute to the processing system. Variables such as flash tank temperature, WFE temperature and level, SPE temperature and level were immediately identified to be significant in the process. These parameters that are identified decoupling the PC are highly logical, as temperature and levels within separators are variables that affect the separation efficiency and thermodynamics of the system. However, lesser significant variables are difficult to be studied in Figure 6 , as the contribution of each variable has not been combined for direct comparison.

Contribution scores of each process variables are reconstructed into a total contribution score. To ease the analysis, the process variables are sorted from the highest contribution score to the lowest with the cumulative contribution score (coverage score) plotted in Figure 7. 


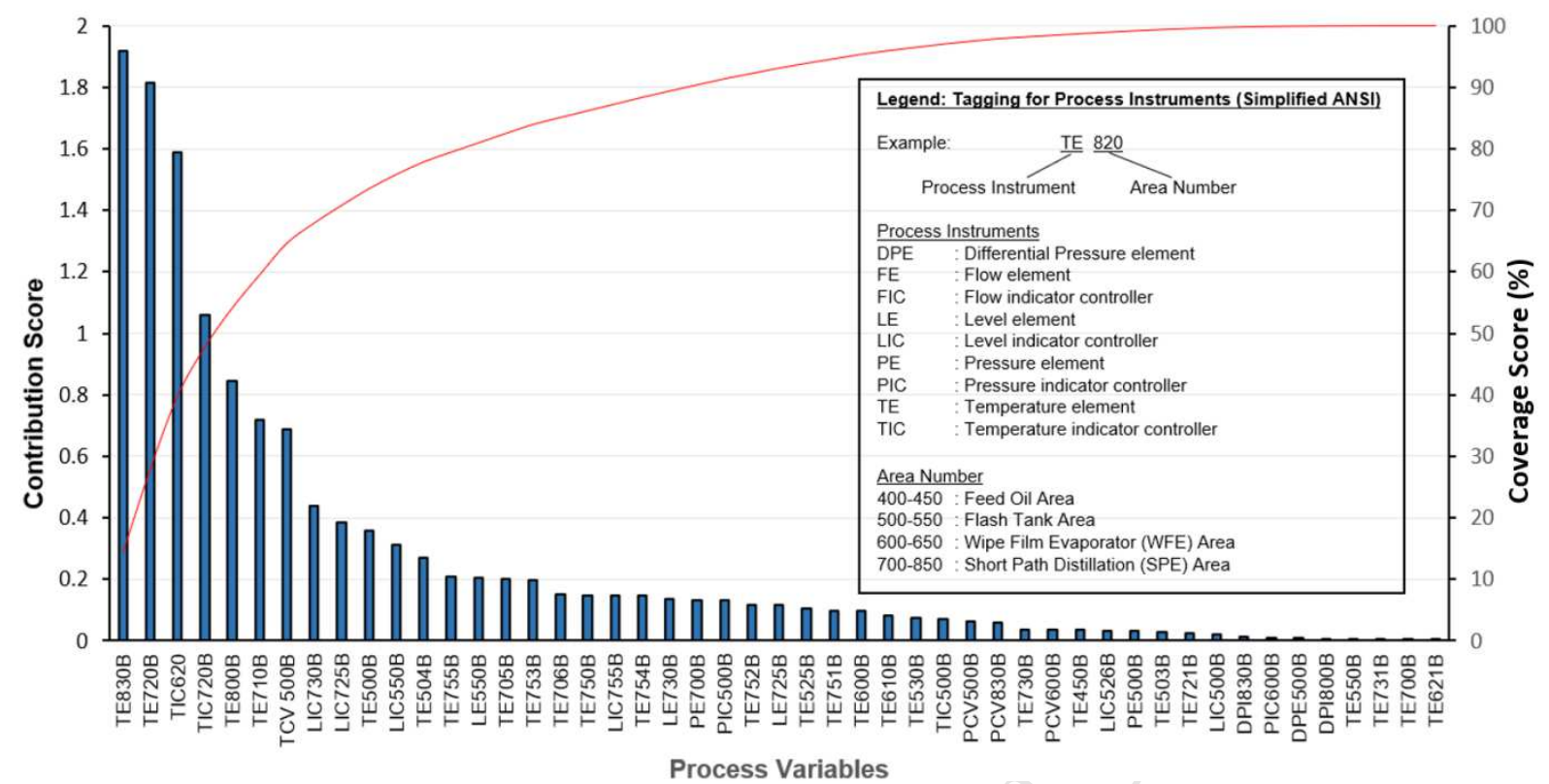

Figure 7: Prioritisation of process variables using contribution score

The factors that will be focused in DoE are operating temperature of the flash tank, WFE, SPE, operating pressure in WFE and SPE, operating level in WFE tank and SPE. These variables are selected based on a $95 \%$ coverage score and can be directly manipulated in the processing system. Furthermore, a study of $80 \%$ and $99 \%$ coverage score was carried out as a comparison. The $80 \%$ cumulative score case considers the temperature of WFE, SPE and flash tank, while $99 \%$ coverage score case considers all variables in $95 \%$ case with the addition of decanter level, decanter pressure and flash tank pressure.

\subsection{Design and Analysis of Experiments}

According to PCA result, factors considered for DoE includes operating temperature of flash tank (A), temperature of WFE (B), temperature of SPE (C), operating pressure of SPE (D), level of WFE (E) and level of SPE $(F)$, while WFE $\left(\mathrm{y}_{1}\right)$ and SPE $\left(\mathrm{y}_{2}\right)$ product flow, WFE $\left(\mathrm{y}_{3}\right)$ viscosity and SPE $\left(\mathrm{y}_{4}\right)$ viscosity are the corresponding response in this study. The factorial design is used to generate desired responses. In addition, the design matrix is shown in Table 8, the " + " and "-" signs represent treatment combinations for the factors. As illustrated, there are seven degrees of freedom (DOF) for eight treatment combinations in which three DOF were associated with main effects of factor A, B, C, D and E.

Table 8: The design matrix for factorial design considering six factors

\begin{tabular}{cccccccc}
\hline Run & A & B & C & D & E & F & Labels \\
\hline 1 & - & - & - & - & - & - & 1 \\
2 & + & - & - & - & - & - & A \\
3 & - & + & - & - & - & - & B
\end{tabular}




\begin{tabular}{|c|c|c|c|c|c|c|c|}
\hline 4 & - & - & + & - & - & - & C \\
\hline 5 & - & - & - & + & - & - & D \\
\hline 6 & - & - & - & - & + & - & $\mathrm{E}$ \\
\hline 7 & - & - & - & - & - & + & $F$ \\
\hline 8 & + & + & - & - & - & - & $A B$ \\
\hline 9 & + & - & + & - & - & - & $A C$ \\
\hline 10 & + & - & - & + & - & - & $A D$ \\
\hline 11 & + & - & - & - & + & - & $A E$ \\
\hline ! & $!$ & ! & 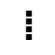 & 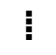 & $!$ & 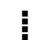 & ! \\
\hline 53 & - & + & + & + & + & - & BCDE \\
\hline 54 & - & + & + & + & - & + & BCDF \\
\hline 55 & - & + & + & - & + & + & BCEF \\
\hline 56 & - & + & - & + & + & + & BDEF \\
\hline 57 & - & - & + & + & + & 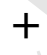 & CDEF \\
\hline 58 & + & + & + & + & + & - & ABCDE \\
\hline 59 & + & + & + & + & $\begin{array}{ll}- \\
-\end{array}$ & + & $A B C D F$ \\
\hline 60 & + & + & + & - & + & + & ABCEF \\
\hline 61 & + & + & - & + & + & + & ABDEF \\
\hline 62 & + & - & + & + & + & + & ACDEF \\
\hline 63 & - & + & + & + & + & + & BCDEF \\
\hline 64 & + & + & + & + & + & + & ABCDEF \\
\hline
\end{tabular}

Subsequently, factors and the responses were fitted with the regression model as shown in Eq.(14). Responses are denoted by $y_{j}$, the regression coefficient is indicated by $\beta_{j}$ whereby $j$ can be any of the desired responses projected by factors considered. Thus, each response will have a dedicated regression model.

The regression model for each response is used to generate a surface response plot as illustrated and explained below. The considered factors are up to $4^{\text {th }}$ order interaction factors, then detrimental factors are removed using hierarchical automatic model selection algorithm with $\mathrm{p}$ values as the criterion. All the considered possibilities of interaction factors considered to give an optimal surface response for $y_{j}$ is shown in the equation below.

$$
\begin{aligned}
y_{j}= & \beta_{0, j}+\beta_{A_{j}} A+\beta_{B_{j}} B+\beta_{C_{j}} C+\beta_{D_{j}} D+\beta_{E_{j}} E+\beta_{F_{j}} F+\beta_{A B_{j}} A B+\beta_{A C_{j}} A C \\
& +\beta_{A D_{j}} A D+\beta_{B C_{j}} B C+\beta_{B D_{j}} B D+\beta_{C D_{j}} C D+\beta_{C E_{j}} C E+\beta_{C F_{j}} C F+\beta_{D E_{j}} D E \\
& +\beta_{D F_{j}} D F+\beta_{E F_{j}} E F+\beta_{A B C_{j}} A B C+\beta_{A B D_{j}} A B D+\beta_{A C D_{j}} A C D+\beta_{B C D_{j}} B C D \\
& +\beta_{C D E_{j}} C D E+\beta_{C D F_{j}} C D F+\beta_{C E F_{j}} C E F+\beta_{D E F_{j}} D E F+\beta_{A B C D_{j}} A B C D
\end{aligned}
$$

Analysis of WFE product flow (LPM) in the assessment of experimental design ranged from 13.97 to 30.65 LPM. The response was fitted in a regression model as shown in eq. (15). 
The most significant effect on the WFE product flow is the WFE temperature (B), which has the largest coefficient of 7.34. An inversely proportional relation can be observed between flash tank temperature (A) and WFE product flow. This is highly possible from the perspectives of separation sciences, as a higher temperature at the flash tank will cause the oil fraction to evaporate into the vapour fraction, reducing the amount of WFE oil products. SPE temperature (C) and pressure (D) have minimal effects on the WFE product flow. This is not surprising since the operating conditions of a downstream separation unit should give minimal effects to the units beforehand. However, level in WFE (E) and SPE (F) contribute to giving a higher WFE product flow, demonstrating positive coefficients of 0.339 and 0.348 respectively. Significant interaction factors are the interaction factors between flash tank temperature, WFE temperature $(A B)$ and WFE level and SPE level (EF). Technically, the contributing interaction factors represent temperatures and levels of consecutive processing units.

In addition, Figure 8 shows that the regression model for WFE product flow as a function of flash, WFE, SPE operating conditions was suitable to investigate the tendency of this response (detailed ANOVA table can be found in Appendix Table 17). Thus, a response surface is generated by plotting two of the main effects with the highest coefficient magnitude (flash and WFE temperature) with respect to the response. Evidently, WFE product flow is dependent on both flash and WFE temperature as illustrated in Figure 9 where the colour of the response surface is warmer when WFE temperature increased and cooler when flash temperature increased. In all, postulation made earlier from the regression model is validated. 


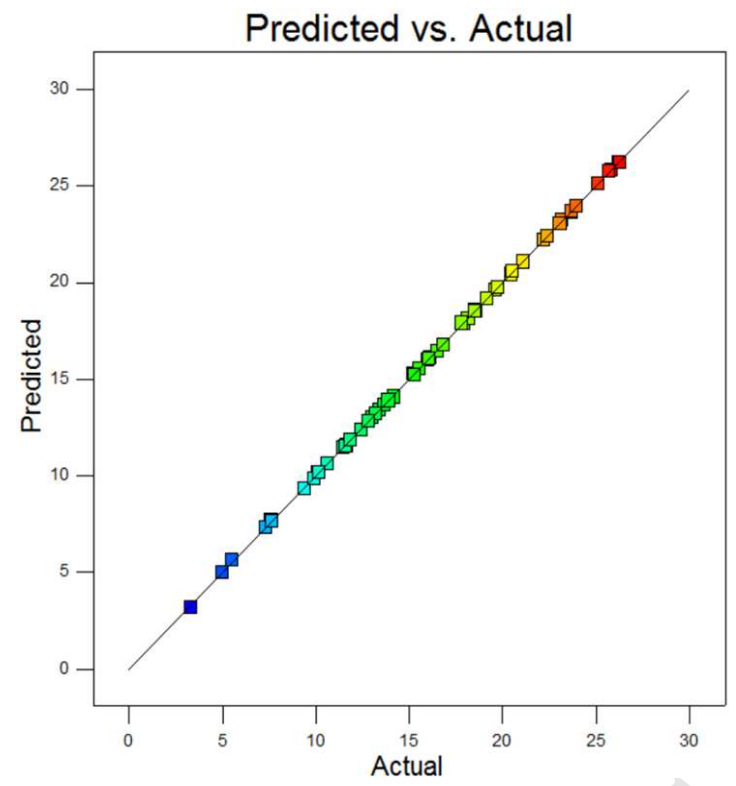

Figure 8: Experimental values for WFE flowrate (LPM) as a function of the values predicted by the fitted model

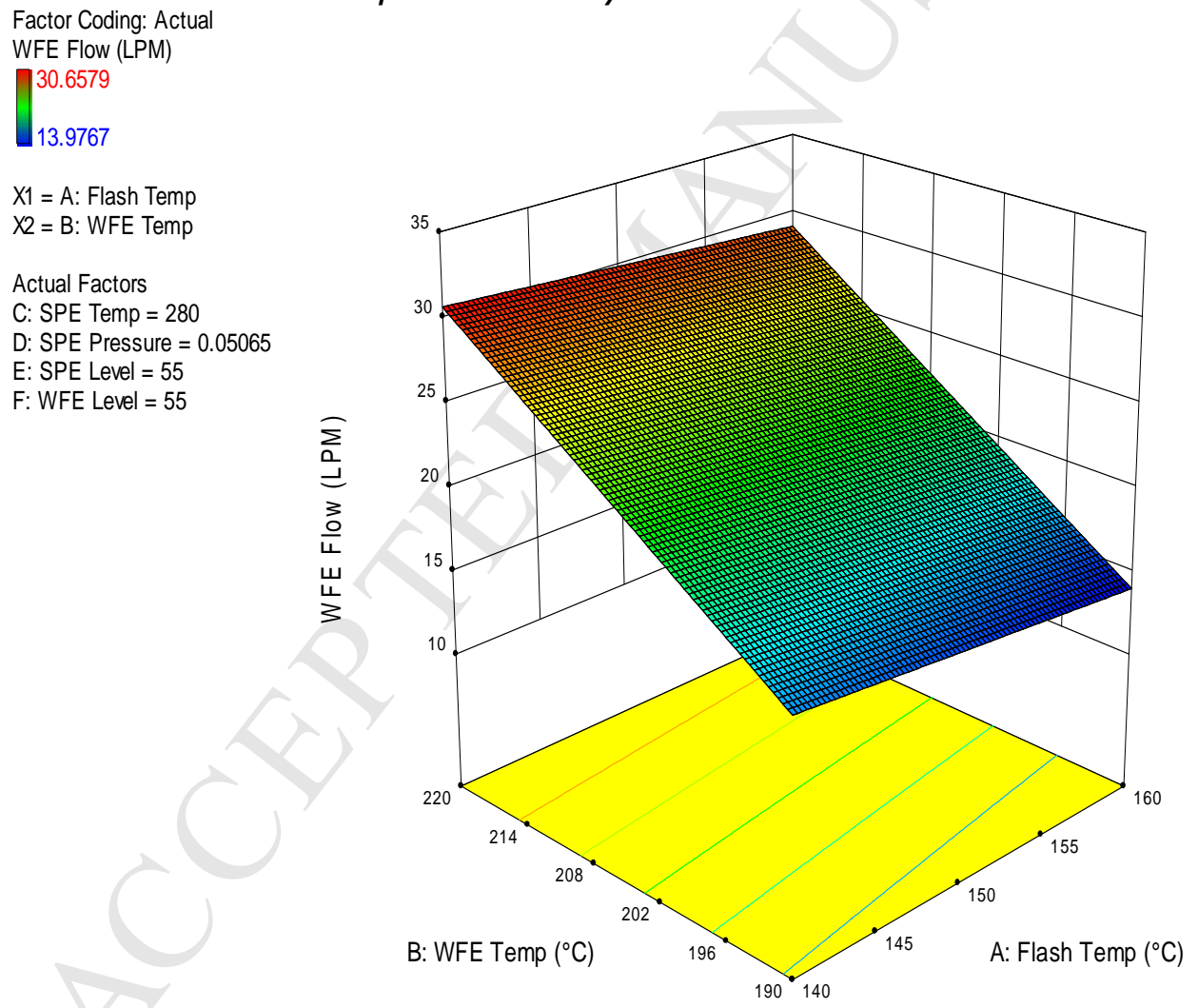

Figure 9: Response surface for WFE flowrate (LPM) as a function of WFE temperature $\left({ }^{\circ} \mathrm{C}\right)$ and Flash tank temperature $\left({ }^{\circ} \mathrm{C}\right)$

Next, analysis of WFE product viscosity (cSt) in the assessment of experimental design ranged from 6.96 to 10.63 cSt is used and the response is fitted in the regression model as shown in eq. (16). (The detailed ANOVA analysis can be found in Appendix Table 18) 
It shows that the relationship of WFE temperatures (B) is proportional to WFE product viscosity with a positive regression coefficient of 1.633 . The viscosity of WFE $\left(\mathrm{y}_{2}\right)$ is found to be inversely proportional to flash temperature (A) and WFE level (E) with a negative coefficient of -0.206 and -0.0214 respectively. A higher temperature in the flash tank causes viscous oil additives within the oil is broken down, giving slightly lower WFE oil viscosity. Besides, at a significantly high level of WFE, the separation efficiency of the evaporator is affected and hence, WFE viscosity decreases. The significant interaction factor is the factor of the flash tank and WFE temperature (AB), which is the temperature interaction of consecutive processing units. Similarly, the WFE flow response, the regression coefficients of the viscosity of the WFE product are not significantly affected by the later process unit (SPE).

In addition, Figure 10 shows that the regression model for WFE product viscosity is appropriate to explore the trend of this response. For validation and visualisation, a response surface is generated using the regression model and shown in Figure 11. From the plot, WFE product viscosity is validated to be dependent on both flash and WFE temperature with stronger dependency for the latter. As illustrated in Figure 11, the colour of the response surface is warmer at the axis of WFE temperature but less warm at the axis of the flash tank temperature.

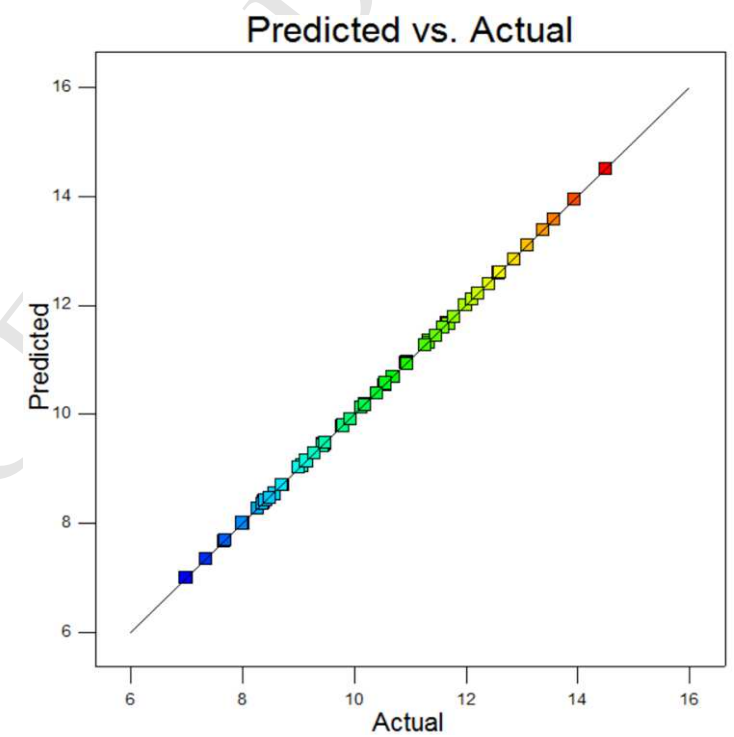

Figure 10: Experimental values for WFE product viscosity (cSt) against of the values predicted 
Factor Coding: Actual

WFE Visc (cSt)

10.6343

6.95882

$\mathrm{X} 1=\mathrm{A}:$ Flash Temp X2 = B: WFE Temp

Actual Factors

C: SPE Temp $=280$

D: SPE Pressure $=0.05065$

E: SPE Level $=55$

F: WFE Level $=55$

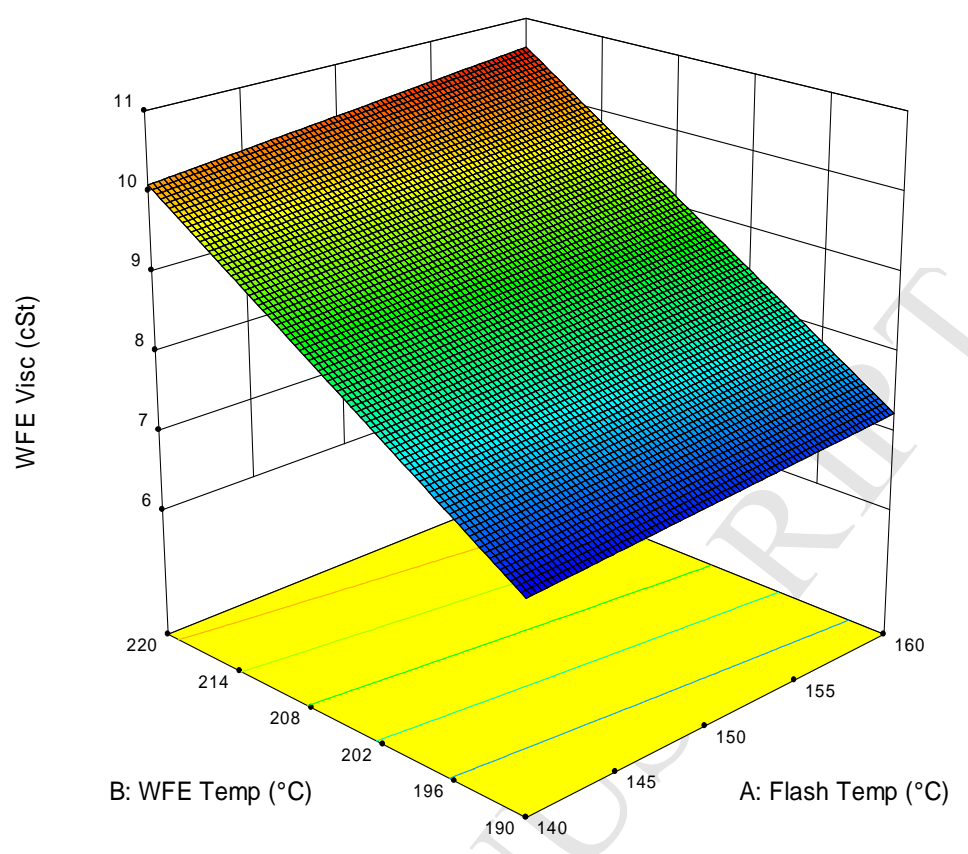

Figure 11: Response surface for WFE product viscosity (cSt) as a function of WFE temperature $\left({ }^{\circ} \mathrm{C}\right.$ ) and Flash tank temperature $\left({ }^{\circ} \mathrm{C}\right)$

Analysis of SPE product flow (LPM) in the assessment of experimental design ranged from 0 to 30.54 LPM is used and the response was fitted in the regression model with regression coefficients as shown in Eq. (17) below. (The detailed ANOVA analysis can be found in Appendix Table 19)

$y_{2}=10.148+0.446 A-5.485 B+11.329 C-8.541 D-0.456 E+0.666 F-4.535 B C+$ $2.095 B C+2.095 B D+4.905 C D+1.383 C F-2.095 D E+3.931 D F-4.113 B C D+$ 5.189CDF

From Eq. (17), the regression coefficients show that SPE product flow is affected by all main effects of Flash tank, WFE and SPE operating conditions. This is logical, as SPE is the final unit in the process and the product flow will depend on upstream units. In addition, Figure 12 shows that the regression model for SPE product flow as a function of flash, WFE, SPE operating condition is fitting to inspect the trend of this response. Thus, a response surface is generated using the regression model as shown in Figure 13. From Figure 13(a), the model predicted that a higher SPE temperature (C) and higher WFE temperature (B) will improve the SPE product flow. Figure 13(b) and (c) also shows that having lower pressure in SFE improves the product flow, while the WFE level gives a slight proportional relationship with product flow. Moreover, increasing the WFE level (E) and SPE temperature (C) simultaneously give high SPE product flowrate. 


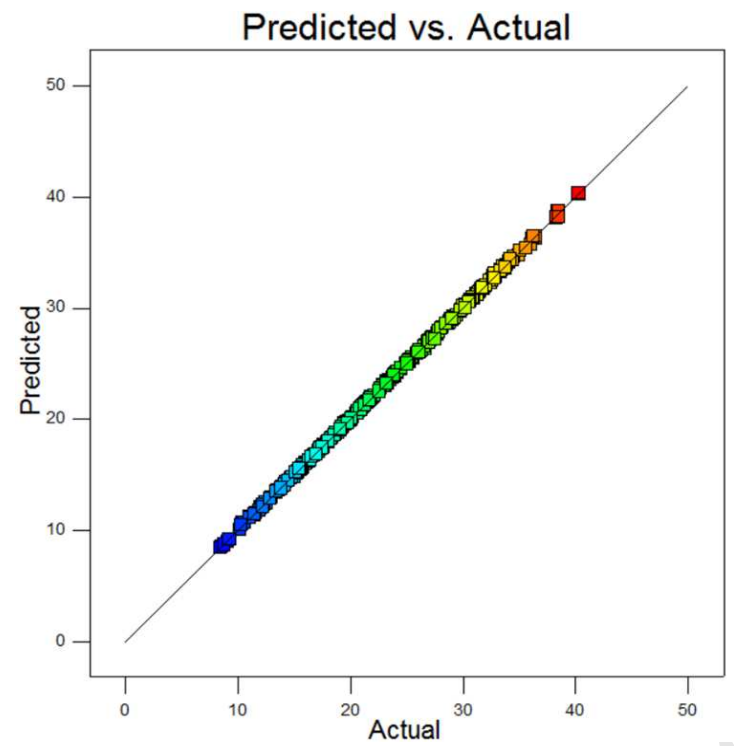

Figure 12: Experimental values for SPE product flow (LPM) against the Factor Coding: Actual values predicted

SPE Flow (LPM)

30.5359

$\mathrm{X} 1=\mathrm{B}:$ WFE Temp X2 $=$ C: SPE Temp

Actual Factors

A: Flash Temp $=150$

D: SPE Pressure $=0.05065$

E: SPE Level $=55$

F: WFE Level $=55$

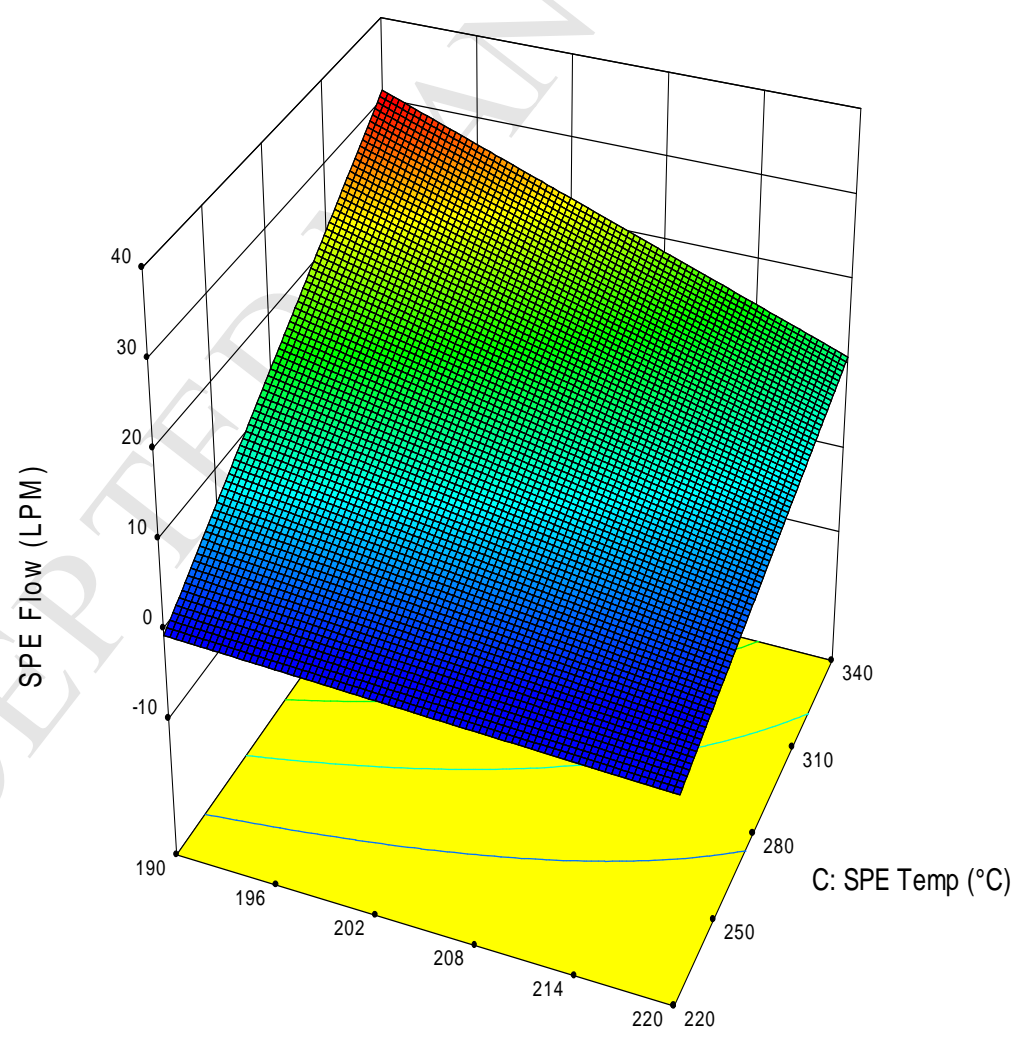

B: WFE Temp $\left({ }^{\circ} \mathrm{C}\right)$

Figure 13 (a) 
Factor Coding: Actual

SPE Flow (LPM)

30.5359

X1 = B: WFE Temp

$\mathrm{X} 2$ = D: SPE Pressure

Actual Factors

A: Flash Temp $=150$

C: SPE Temp $=280$

E: SPE Level $=55$

F: WFE Level $=55$

Factor Coding: Actual SPE Flow (LPM)

30.5359

0

X1 = C: SPE Temp $X 2$ = F: WFE Level

Actual Factors

A: Flash Temp $=150$

B: WFE Temp $=205$

D: SPE Pressure $=0.05065$

E: SPE Level $=55$

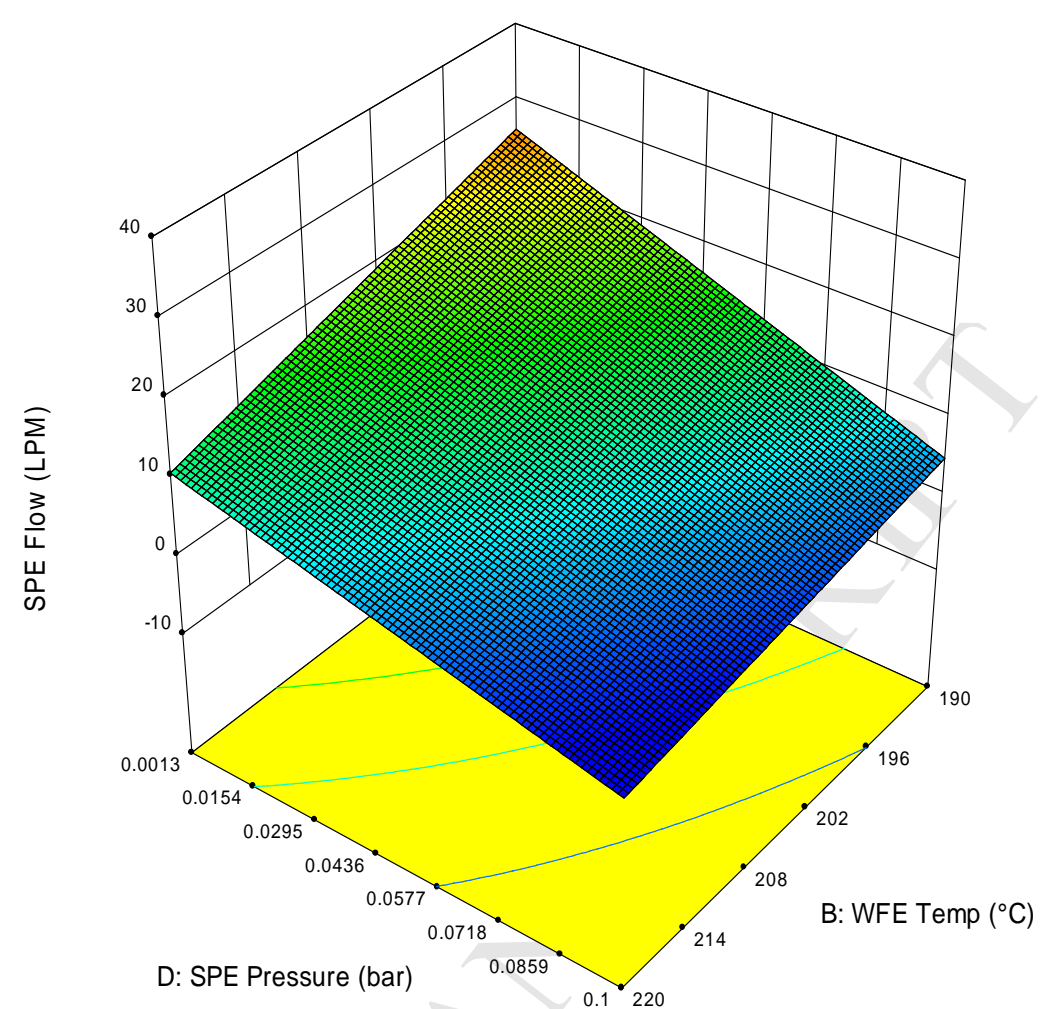

Figure 13 (b)

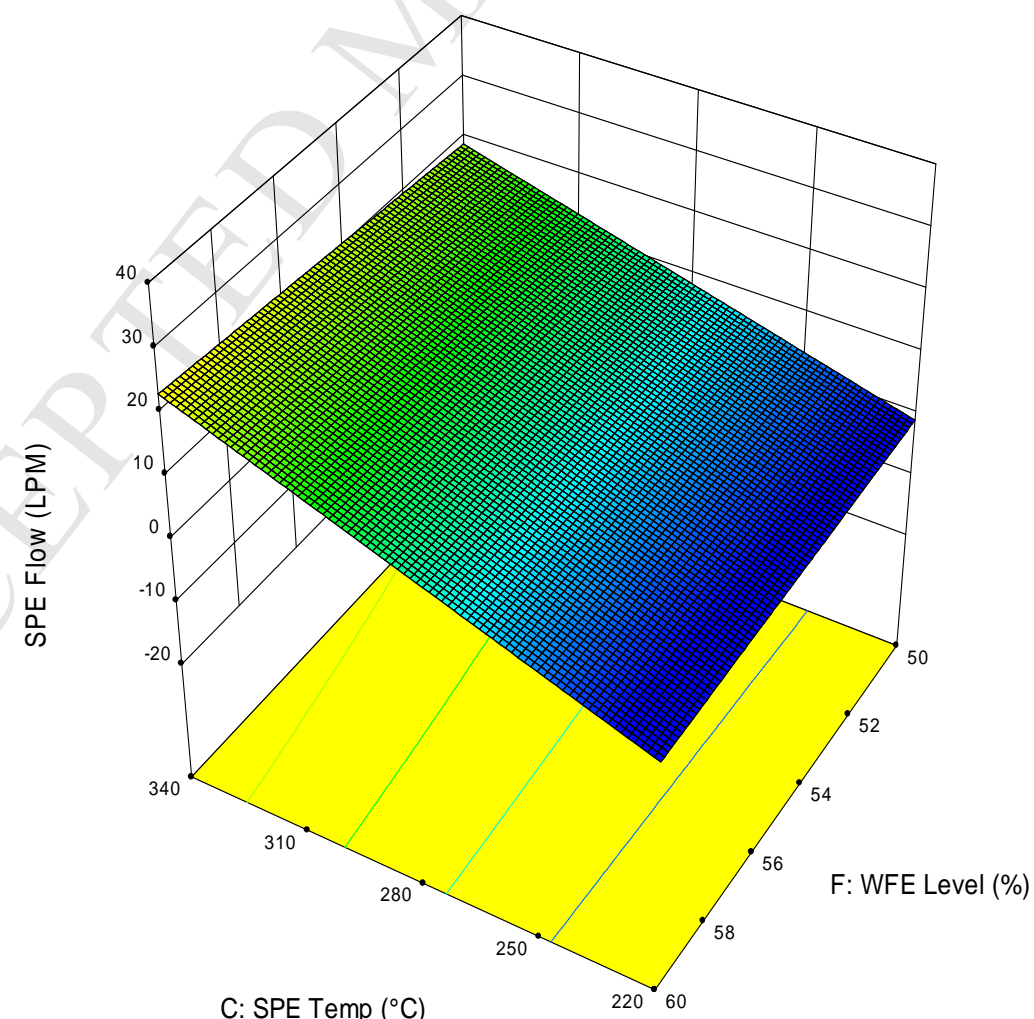

Figure 13 (c)

Figure 13: Response surface for SPE product flow (LPM) as a function of:

(a) WFE temperature $\left({ }^{\circ} \mathrm{C}\right)$ and SPE temperature $\left({ }^{\circ} \mathrm{C}\right)$

(b) SPE pressure (bar) and WFE temperature $\left({ }^{\circ} \mathrm{C}\right)$ 
(c) SPE temperature $\left({ }^{\circ} \mathrm{C}\right)$ and WFE level (\%)

Analysis of SPE product viscosity (cSt) in the assessment of experimental design ranged from 8.5 to $43.8 \mathrm{cSt}$ is used and the response is fitted in the regression model with regression coefficients listed in Eq. (18).(The detailed ANOVA analysis can be found in Appendix Table 20)

$y_{3}=19.527+1.357 B+10.134 C-8.257 D+4.714 B C-4.842 B D+1.961 C D+$

$7.806 C F+9.512 C D F$

From Eq. (18), the SPE product viscosity mainly depends on SPE pressure (D) and temperature (C), as well as the WFE temperature (B). Thus, a response surface is generated using the regression model as shown in Figure 14. Subsequently, SPE product viscosity is found to improve with the simultaneous increase of SPE temperature and of WFE temperature from Figure 14(a). A similar relation to the SPE flow is found with the SPE pressure and level from Figure 14(b), in which a lower SPE pressure and higher WFE temperature give better product viscosity. This shows that lowering pressure while maintaining a high temperature in both SPE and WFE can improve SPE separation quality and yield.
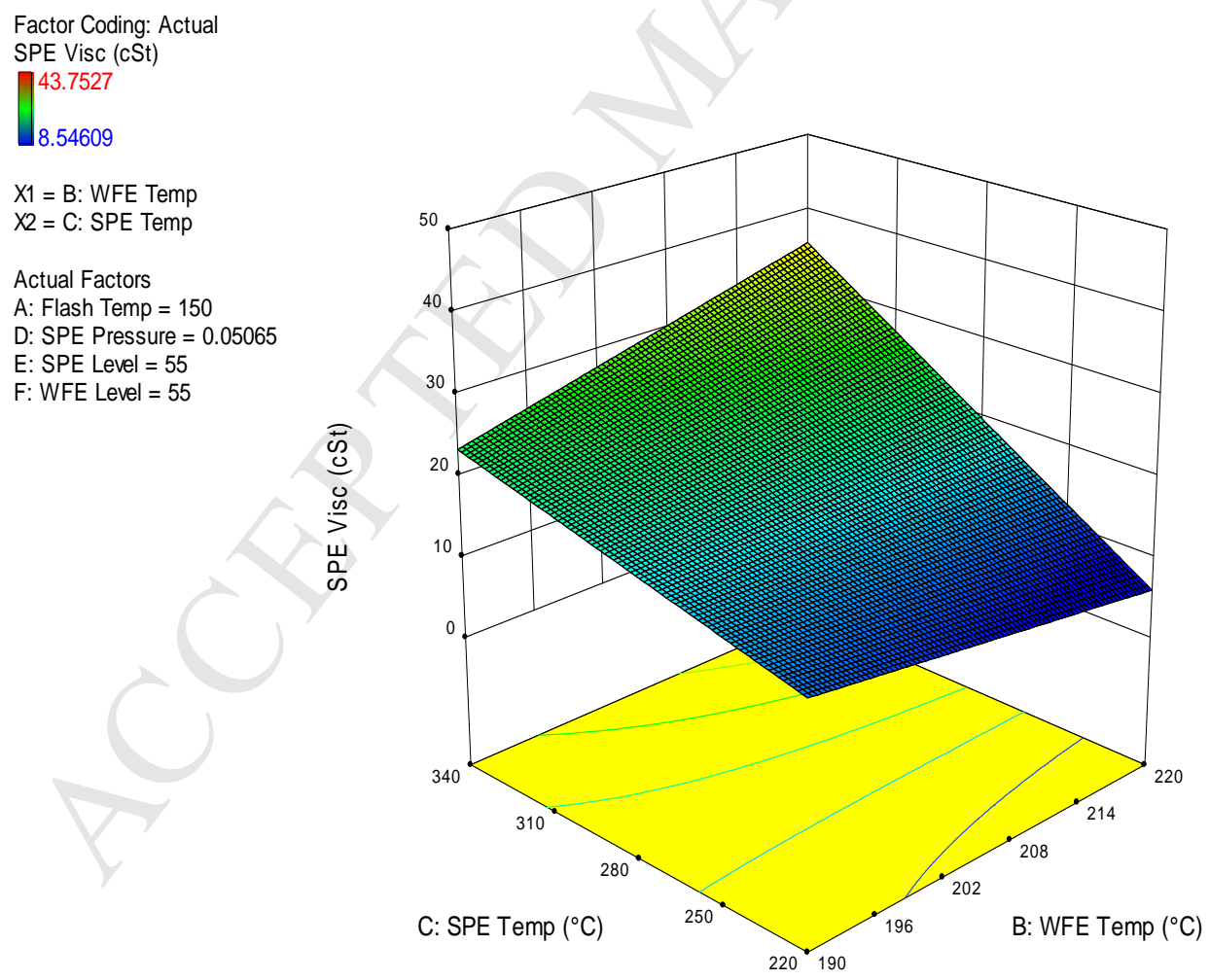

Figure 14(a) 
Factor Coding: Actual

SPE Visc (cSt)

43.7527

8.54609

X1 = B: WFE Temp X2 = D: SPE Pressure

Actual Factors

A: Flash Temp $=150$

C: SPE Temp $=280$

E: SPE Level $=55$

F: WFE Level $=55$

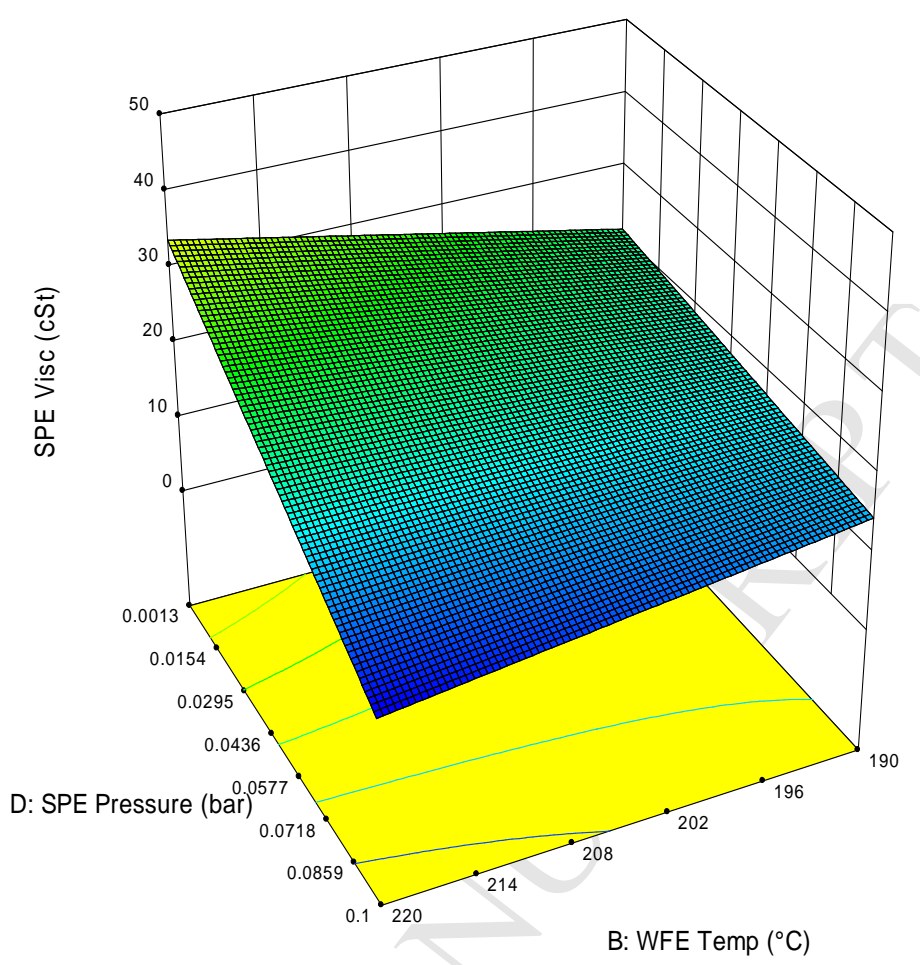

Figure 14(b)

Figure 14: Response surface for SPE product viscosity (cSt) as a function of:

(a) WFE temperature $\left({ }^{\circ} \mathrm{C}\right)$ and SPE temperature $\left({ }^{\circ} \mathrm{C}\right)$ WFE temperature $\left({ }^{\circ} \mathrm{C}\right.$ ) and SPE pressure (bar)

From the surface responses, the optimal operating temperatures of the flash tank, WFE and SPE are successfully established. To aid the understanding of the optimal combination of operating conditions for flash, WFE and SPE, an operating condition solution graph is plotted as illustrated in Figure 15. In details, Figure15(a), (b), (c), (d), (e) and (f) represent factors, while Figure $15(\mathrm{~g}),(\mathrm{h}),(\mathrm{i})$ and $(\mathrm{j})$ represent the responses. Moreover, the factors in Figure 15(a), (b) and (c) are varied between their respective minimum and maximum operating temperatures denoted by the vertical boundary based on the actual capabilities of processing equipment. Furthermore, the vertical boundaries in Figure $15(\mathrm{~g})$ and $(\mathrm{h})$ are the process limit for WFE and SPE product viscosity. Note that higher viscosity is preferred for products of WFE and SPE. 


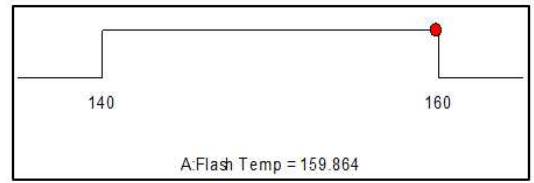

(a)

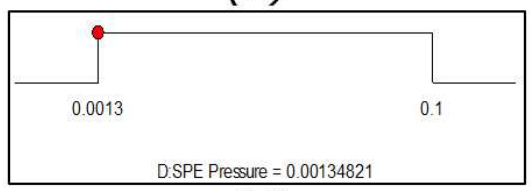

(d)

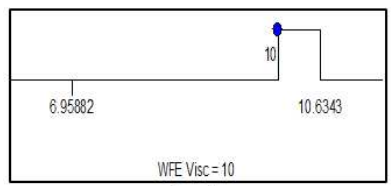

(g)

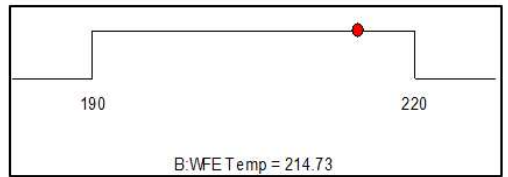

(b)

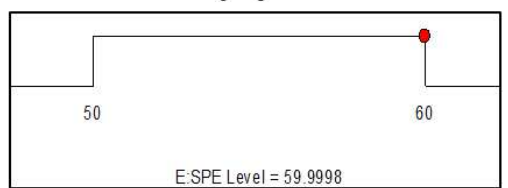

(e)

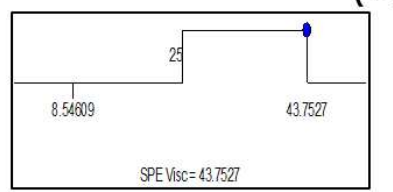

(h)

(i)

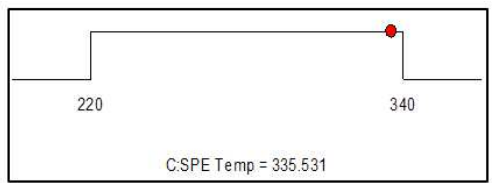

(c)

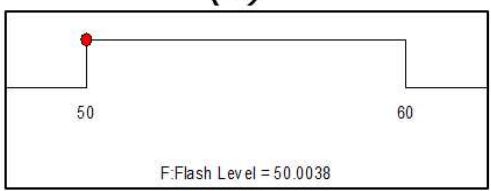

(f)

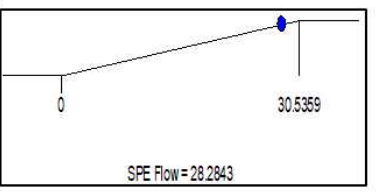

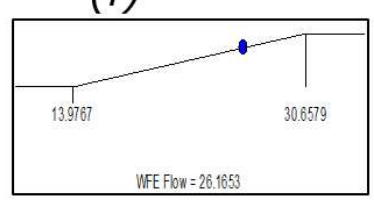

(j)

Figure 15: Optimisation solution diagram

(a) Operating temperature of flash tank

(b) Operating temperature of WFE

(c) Operating temperature of SPE

(d) Operating pressure of SPE

(e) Operating level of SPE (f) Operating level of WFE

(g) WFE product flow (LPM)

(h) WFE product viscosity (cSt)

(i) SPE product flow (LPM)

(j) SPE product viscosity (cSt)

Finally, comparisons between the factors and responses before and after statistical optimisation are shown in Table 9. Tremendous improvements are clearly seen in SPE product for its throughput (flow) at $84.4 \%$ and quality (viscosity) at $46.5 \%$. This is achieved by lowering operating temperatures of the flash tank as much as $28.2 \%$ and $5.8 \%$ for WFE but an increase of $45.2 \%$ for SPE. The pressure in SPE remains unchanged while the level in the WFE and SPE increased by $9.1 \%$ and $20 \%$ respectively (two-tailed t-test can be found in Appendix Table 22).

Table 9: Comparisons between the factors and responses prior to and after optimisation

\begin{tabular}{ccccc}
\hline Process parameters & Units & Before & After & Change (\%) \\
\hline Flash Tank Temperature & $\left({ }^{\circ} \mathrm{C}\right)$ & 222.6 & 159.86 & 28.2 \\
WFE Temperature & $\left({ }^{\circ} \mathrm{C}\right)$ & 228 & 214.73 & 5.8 \\
SPE Temperature & $\left({ }^{\circ} \mathrm{C}\right)$ & 231 & 335.5 & 45.2 \\
SPE Pressure & $(\mathrm{bar})$ & 0.0013 & 0.0013 & 0.0 \\
WFE Level & $(\%)$ & 55 & 50.0 & 9.1 \\
SPE Level & $(\%)$ & 50 & 60 & 20.0 \\
WFE Product Flow & $(\mathrm{LPM})$ & 20.75 & 26.16 & 26.1 \\
WFE Product Viscosity & $(\mathrm{cSt})$ & 10.56 & 10.0 & 5.3 \\
SPE Product Flow & $(\mathrm{LPM})$ & 15.34 & 28.28 & 84.4 \\
SPE Product Viscosity & $(\mathrm{cSt})$ & 29.86 & 43.75 & 46.5 \\
\hline
\end{tabular}




\subsection{Optimisation Results of Different Coverage Scores}

Different coverage scores from the PCA model is used for DoE optimisation. Coverage scores of $80 \%, 95 \%$ and $99 \%$ (100\% coverage score requires $49 \mathrm{DoE}$ factors and resulting in $5.6 \times 10^{14}$ number of runs) are used to benchmark the optimisation results. Each design will require an increase in DoE factors which, in return increases the number of runs. The optimised results are benchmarked in Table 10.

Table 10: Comparisons between the $80 \%, 95 \%$ and $99 \%$ coverage score (C.S.) optimisation

\begin{tabular}{ccccccc}
\hline Variables & Unit & $\begin{array}{c}\mathbf{8 0} \% \\
\text { C.S. } \\
\text { (A) }\end{array}$ & $\begin{array}{c}\text { Change } \\
(\%)\end{array}$ & $\begin{array}{c}\mathbf{9 5 \%} \\
\text { C.S. } \\
\text { (B) }\end{array}$ & $\begin{array}{c}\text { Change } \\
\text { (\%) }\end{array}$ & $\begin{array}{c}\mathbf{9 9 \%} \\
\text { C.S. } \\
\text { (C) }\end{array}$ \\
\hline $\begin{array}{c}\text { DoE } \\
\text { Factors }\end{array}$ & - & 3 & - & 6 & - & 17 \\
\hline $\begin{array}{c}\text { Minimum } \\
\text { Number } \\
\text { of Runs }\end{array}$ & - & 8 & - & 64 & - & 262144 \\
\hline $\begin{array}{c}\text { Coverage } \\
\text { Variance }\end{array}$ & $\%$ & 80 & - & 95 & - & 99 \\
\hline $\begin{array}{c}\text { WFE } \\
\text { Product } \\
\text { Flow }\end{array}$ & LPM & 20.74 & 26.13 & 26.16 & 10.28 & 28.85 \\
\hline $\begin{array}{c}\text { WFE } \\
\text { Product } \\
\text { Viscosity }\end{array}$ & CSt & 10.00 & 0.00 & 10.00 & 0.00 & 10.00 \\
\hline $\begin{array}{c}\text { SPE } \\
\text { Product } \\
\text { Flow }\end{array}$ & LPM & 23.66 & 19.53 & 28.28 & 2.58 & 29.01 \\
\hline $\begin{array}{c}\text { SPE } \\
\text { Product } \\
\text { Viscosity }\end{array}$ & CSt & 38.08 & 14.89 & 43.75 & 6.17 & 46.45 \\
\hline
\end{tabular}

From the table above, Case $C$ is taken as the comparison basis since the coverage score is nearest to including the full process system. Improving the optimisation model from a coverage score of $80 \%$ to $95 \%$ (Case A to B) gives an averaged deviation of $15.1 \%$. However, this work recommends a higher quality of optimisation coverage, which is $95 \%$. This is shown when the optimisation model is improved from $95 \%$ to $99 \%$ coverage, in which the averaged deviation is $4.75 \%$. The small improvements in optimisation results are not justified for the incurring 
capital cost for 262080 extra experimental runs (4095 folds compared to Case B). Therefore, the $95 \%$ coverage score (Case B) used for this work is effective and efficient.

\subsection{Process Cycle Assessment}

The impact categories chosen to access environmental impacts for this case study are global warming potential (GWP) and acidification potential (AP). Standard indicators for GWP and AP which are carbon dioxide $\left(\mathrm{CO}_{2}\right)$ and sulphur dioxide $\left(\mathrm{SO}_{2}\right)$ equivalent are used respectively since it is common for oil products contaminated with hydrogen sulphide $\left(\mathrm{H}_{2} \mathrm{~S}\right)$. Thus, characterisation models for conversion of natural and electricity to $\mathrm{CO}_{2}$ equivalent are shown in Table 11 . Similarly, characterisation model for conversion of $\mathrm{H}_{2} \mathrm{~S}$ to $\mathrm{SO}_{2}$ equivalent is shown in Table 12.

Table 11: Characterisation model for GWP (The Carbon Trust, 2011)

\begin{tabular}{ccc}
\hline Energy & Natural gas & \\
combustion & Grid Electricity \\
\hline Units & $\mathrm{kWh}$ & $\mathrm{kWh}$ \\
$\mathrm{GWP}\left(\mathrm{kgCO}_{2}^{-1}\right)$ & 5.3808 & 0.5246 \\
\hline
\end{tabular}

Table 12: Characterisation model for AP (The Carbon Trust, 2011)

$\begin{array}{cc}\text { Acid Producer } & \text { Hydrogen Sulphide }\left(\mathbf{H}_{\mathbf{2}} \mathbf{S}\right) \\ \text { Units } & \mathrm{kg} \\ \mathrm{AP}\left(\mathrm{kgSO}_{2}^{-1}\right) & 1.88 \\ \end{array}$

With the appropriate characterisation models, data for utilities, energy consumption and fractions of $\mathrm{H}_{2} \mathrm{~S}$ in oil products are extracted from the simulation model and compared for both cases of before and after statistical process optimisation. Calculated results are shown in Table 13, Table 14and compared in Table 15.

Table 13: GWP for combustion of natural gas in furnace and electricity consumption for pump

\begin{tabular}{ccccccc}
\hline \multirow{2}{*}{ Units } & \multicolumn{3}{c}{ Furnace } & \multicolumn{3}{c}{ Pump } \\
\cline { 2 - 7 } & Before & After & $\begin{array}{c}\text { \% } \\
\text { Change }\end{array}$ & Before & After & $\begin{array}{c}\text { \% } \\
\text { Change }\end{array}$ \\
\hline $\begin{array}{c}\text { Energy } \\
(\mathrm{kWh}) \\
\begin{array}{c}\mathrm{GWP} \\
\left(\mathrm{kgCO}_{2}^{-1}\right)\end{array}\end{array}$ & 93389.1 & 90139.6 & & 763.9 & 757.3 & \\
\hline
\end{tabular}

Table 14: AP for by-products and main products in the process 


\begin{tabular}{|c|c|c|c|c|c|c|}
\hline \multirow{2}{*}{ Product } & \multicolumn{3}{|c|}{ WFE } & \multicolumn{3}{|c|}{ SPE } \\
\hline & Before & After & $\begin{array}{c}\% \\
\text { Change }\end{array}$ & Before & After & $\begin{array}{c}\% \\
\text { Change }\end{array}$ \\
\hline $\mathrm{H}_{2} \mathrm{~S}(\mathrm{~kg})$ & 0.0057 & 0.0007 & \multirow{2}{*}{156.2} & 0.00 & 0.00 & \\
\hline $\mathrm{AP}\left(\mathrm{kgSO}_{2}{ }^{-1}\right)$ & 0.01 & 0.00 & & 0.00 & 0.00 & \\
\hline \multirow{2}{*}{ Product } & \multicolumn{3}{|c|}{ Lights } & \multicolumn{3}{|c|}{ Oil water } \\
\hline & Before & After & $\begin{array}{c}\% \% \\
\text { Change } \\
\end{array}$ & Before & After & $\begin{array}{c}\% \\
\text { Change }\end{array}$ \\
\hline $\mathrm{H}_{2} \mathrm{~S}(\mathrm{~kg})$ & 62.11 & 4.80 & 171.3 & 1.02 & 0.95 & 71 \\
\hline $\operatorname{AP}\left(\mathrm{kgSO}^{-1}\right)$ & 116.76 & 9.03 & & 1.92 & 1.78 & \\
\hline \multirow{2}{*}{ Product } & \multicolumn{3}{|c|}{ Asphalt } & & & \\
\hline & Before & After & $\begin{array}{c}\% \\
\text { Change } \\
\end{array}$ & & & \\
\hline $\mathrm{H}_{2} \mathrm{~S}(\mathrm{~kg})$ & 0.00 & 0.00 & & & & \\
\hline $\mathrm{AP}\left(\mathrm{kgSO}^{-1}\right)$ & 0.00 & 0.00 & & & & \\
\hline
\end{tabular}

Table 15: Comparison of environmental performance for before and after statistical process optimisation

\begin{tabular}{ccccccc}
\hline $\begin{array}{c}\text { Impact } \\
\text { category }\end{array}$ & Before & After & $\begin{array}{c}\text { \% } \\
\text { Change }\end{array}$ & Before & After & $\begin{array}{c}\% \\
\text { Change }\end{array}$ \\
\cline { 2 - 7 } Value & 17546.9 & 16946.9 & 3.42 & 118.7 & 10.8 & 90.89 \\
\hline
\end{tabular}

Ultimately, statistical process optimisation has helped to achieve a leaner process by reducing the consumption of energy while improving product throughput and quality (Table 9). In addition, benefits extended to the environmental performances as GWP and AP assessed have witnessed immense improvement as shown in Table 15. Although it may be argued that GWP improvement is merely $3.42 \%$ but it is remarkable considering that no additional investment cost is required. Moreover, operating cost decreased due to reductions in energy and utility consumption. Furthermore, AP improved $90.89 \%$ which means that product or byproduct sold to consumers will pose a significantly lesser environmental 
threat. To conclude, the process achieved lean and green after statistical process optimisation.

\subsection{Conclusion}

In this work, a novel framework (PASPO) which integrates the use of process simulation, PCA, DoE and process cycle assessment is developed. The PASPO framework aims to provide a cost-effective and systematic way for process optimisation in the real chemical plant with the consideration of environmental impacts. Data from plant data historian are normally very big data sets that are difficult to be analysed. The significance of the PASPO framework is that it transforms plant operational data as the driving force for a practical and sensible plantwide optimisation study. To elucidate the applicability and effectiveness of the PASPO framework, a real industrial case study of a waste oil rerefining plant (Pentas Flora Sdn. Bhd.) is carried out. This framework utilizes a novel correlational-based PCA implementation, in which processing variables are dimensionally reduced by both principal component's cumulative variance and variable contribution score. After applying the PASPO framework, optimised operating conditions gave an increase in SPE product (main product) yield of $84.4 \%$ and WFE product improved by $26.1 \%$. The quality of SPE also increased by $46.5 \%$. In addition, results from DoE were assessed from the ecological point of view with process cycle assessment. The optimised processing conditions had improved Global Warming Potential (GWP) by $3.42 \%$ and Acidification Potential (AP) by $90.89 \%$. With the aid of this framework, the waste oil re-refining plant can transform towards a leaner and greener operation. Evidently, emissions are reduced simultaneously with the enhancement of product throughput and quality. In all, the novel PASPO framework proposed has high potential in guiding engineers to design a sustainable process that considers the allowance for future expansions.

The main limitation in implementing the PASPO framework within a process plant is it requires a considerable amount of historical data on the whole process system to be used as input to the framework. This can be a major challenge for the antiquated processing systems or plants, as sampling instruments may be not as readily available. Furthermore, this work only covers the improvement of process systems from an operational perspective. The approach only targets improvements by altering the operating conditions of processing systems. The PASPO framework can be extended to include the debottlenecking studies of process systems by modifying equipment capacities. Future work will cover the extension of PASPO framework to include equipment capacities and alternative novel multi-objective techniques. 


\section{Acknowledgement}

Research funding and support from Newton Fund and the EPSRC/RCUK (Grant Number: EP/PO18165/1) is gratefully acknowledged. Immense gratitude towards Pentas Flora Sdn. Bhd. for approving the case study to be carried out and performing lab test in their respected laboratory. Special thanks to Mr. Donny Goh and Ms. Tan Yuan Ni of Pentas Flora laboratory team.

\section{Nomenclature}

Abbreviation

WFE

Wiped Film Evaporator

SPE Short Path Evaporator

DoE Design of Experiment

GWP Global Warming Potential

PCA Principal Component Analysis

H2S Hydrogen Sulphite

$\mathrm{CO} 2$ Carbon Dioxide

SO2 Sulphur Dioxide

LCA Life Cycle Analysis

LPM Liters Per Minute

GCMS Gas Chromatography-mass Spectrometry

AP Acidification Potential

GHG Greenhouse Gases

ISO International Standard Organisation 


\section{Appendix}

The following is the paired t-test results for simulated and actual data. The results gave a $\mathrm{p}$-value of 0.1384 (the difference is not statistically significant). The $95 \%$ confidence interval is from -8.6837 to 43.2157 with a mean of 17.2660 .

Table 16: Paired t-test parameters $(t=1.8473, d t=4$, standard error of difference $=9.346$ )

\begin{tabular}{ccc}
\hline Group & Simulated Data & Actual Data \\
\hline Mean & 554.522 & 537.256 \\
\hline SD & 483.6589 & 470.1995 \\
\hline SEM & 216.2988 & 210.2796 \\
\hline N & 5 & 5 \\
\hline
\end{tabular}

The following are the regression coefficient and the statistical analysis of the design of experiment (DoE).

Table 17: Regression coefficients and ANOVA for the response of WFE product flow (LPM)

\begin{tabular}{ccccc}
\hline Source & Coefficient & $\begin{array}{c}\text { Sum of } \\
\text { Squares }\end{array}$ & F-value & $\begin{array}{c}\text { p-value } \\
\text { (Prob }>\text { F) }\end{array}$ \\
\hline Model & - & 16415.1560 & 116358.8793 & $<0.0001$ \\
\hline Intercept & 22.6013 & - & - & - \\
\hline $\begin{array}{c}\text { A-Flash } \\
\text { Temp }\end{array}$ & -1.0031 & 275.1277 & 11701.4628 & $<0.0001$ \\
\hline $\begin{array}{c}\text { B-WFE } \\
\text { Temp }\end{array}$ & 7.3449 & 11906.2998 & 506387.0382 & $<0.0001$ \\
\hline $\begin{array}{c}\text { E-SPE } \\
\text { Level }\end{array}$ & 0.3393 & 1.2691 & 53.9769 & $<0.0001$ \\
\hline $\begin{array}{c}\text { F-WFE } \\
\text { Level }\end{array}$ & 0.3483 & 0.6430 & 27.3466 & $<0.0001$ \\
\hline AB & 0.2099 & 5.7274 & 243.5931 & $<0.0001$ \\
\hline EF & 0.3393 & 0.5066 & 21.5483 & $<0.0001$ \\
\hline Residual & - & 12.5085 & - & - \\
\hline Cor Total & - & 16765.5081 & - & - \\
\hline A-Flash temp & - & & - & \\
\hline
\end{tabular}

A-Flash temperature; B-WFE Temperature; C-SPE Temperature; D-SPE Pressure; E-SPE Level; F- WFE Level 
Table 18: Regression coefficients and ANOVA for response of WFE product viscosity (cSt)

\begin{tabular}{ccccc}
\hline Source & Coefficient & $\begin{array}{c}\text { Sum of } \\
\text { Squares }\end{array}$ & F-value & $\begin{array}{c}\text { p-value } \\
\text { (Prob }>\text { F) }\end{array}$ \\
\hline $\begin{array}{c}\text { Model } \\
\text { Intercept }\end{array}$ & - & 786.9929 & 165126.4812 & $<0.0001$ \\
$\begin{array}{c}\text { A-Flash } \\
\text { Temp }\end{array}$ & 0.2055 & 12.4209 & 10424.5553 & $<0.0001$ \\
\hline $\begin{array}{c}\text { B-WFE } \\
\text { Temp }\end{array}$ & 1.6331 & 638.0008 & 535460.1176 & $<0.0001$ \\
\hline $\begin{array}{c}\text { E-SPE } \\
\text { Level }\end{array}$ & -0.0214 & 0.0108 & 9.0462 & 0.0028 \\
\hline AB & 0.0493 & 0.3514 & 294.9067 & $<0.0001$ \\
\hline Residual & - & 0.6363 & - & - \\
\hline Cor Total & - & 812.9685 & - & - \\
\hline A-Fash
\end{tabular}

A-Flash temperature; B-WFE Temperature; C-SPE Temperature; D-SPE Pressure; E-SPE Level; F- WFE Level

Table 19: Regression coefficients and ANOVA for the response of SPE product flow (LPM)

\begin{tabular}{ccccc}
\hline Source & Coefficient & $\begin{array}{c}\text { Sum of } \\
\text { Squares }\end{array}$ & F-value & $\begin{array}{c}\text { p-value } \\
\text { (Prob }>\text { F) }\end{array}$ \\
\hline $\begin{array}{c}\text { Model } \\
\text { Intercept }\end{array}$ & $\begin{array}{c}\text { Pquars } \\
\text { A-Flash } \\
\text { Temp }\end{array}$ & 52398.7500 & 236.2309 & $<0.0001$ \\
\hline $\begin{array}{c}\text { B-WFE } \\
\text { Temp }\end{array}$ & -5.4853 & - & - & - \\
\hline $\begin{array}{c}\text { C-SPE } \\
\text { Temp }\end{array}$ & 11.3287 & 60.5451 & 3.8214 & 0.0300 \\
\hline $\begin{array}{c}\text { D-SPE } \\
\text { Pressure }\end{array}$ & -8.5408 & 11734.2456 & 740.6261 & $<0.0001$ \\
\hline $\begin{array}{c}\text { E-SPE } \\
\text { Level }\end{array}$ & -0.4555 & 12.4843 & 5.1568 & 0.0492 \\
\hline $\begin{array}{c}\text { F-WFE } \\
\text { Level }\end{array}$ & 0.6656 & 13.2176 & 7.2031 & 0.0452 \\
\hline BC & -4.5353 & 1975.1285 & 124.6635 & $<0.0001$ \\
\hline BD & 2.0954 & 367.1878 & 23.1757 & $<0.0001$ \\
\hline CD & 4.9047 & 1647.7490 & 104.0004 & $<0.0001$ \\
\hline CF & 1.3832 & 17.2610 & 10.4583 & 0.0499 \\
\hline DE & -2.0946 & 26.1982 & 6.6535 & 0.0199 \\
\hline DF & 3.9307 & 53.9186 & 3.4032 & 0.0456 \\
\hline BCD & -4.1132 & 604.7040 & 38.1669 & $<0.0001$ \\
\hline CDF & 5.1890 & 53.5888 & 3.3823 & 0.0365 \\
\hline Residual & - & 8302.0906 & - & - \\
\hline
\end{tabular}


A-Flash temperature; B-WFE Temperature; C-SPE Temperature; D-SPE

Pressure; E-SPE Level; F- WFE Level

Table 20: Regression coefficients for the response of SPE product viscosity (cSt) as a function of flash, WFE and SPE temperature $\left({ }^{\circ} \mathrm{C}\right.$ )

\begin{tabular}{|c|c|c|c|c|}
\hline Factor & Coefficient & $\begin{array}{l}\text { Sum of } \\
\text { Squares }\end{array}$ & F-value & $\begin{array}{c}\text { p-value } \\
\text { (Prob>F) }\end{array}$ \\
\hline Model & - & 39819.2607 & 208.1621 & $<0.0001$ \\
\hline Intercept & 19.5272 & - & - & - \\
\hline $\begin{array}{l}\text { B-WFE } \\
\text { Temp }\end{array}$ & 1.3569 & 472.7502 & 19.7711 & $<0.0001$ \\
\hline $\begin{array}{l}\text { C-SPE } \\
\text { Temp }\end{array}$ & 10.1338 & 19782.9625 & 827.3510 & $<0.0001$ \\
\hline $\begin{array}{c}\text { D-SPE } \\
\text { Pressure }\end{array}$ & -8.2566 & 11825.1727 & 494.5452 & $<0.0001$ \\
\hline BC & 4.7141 & 2531.0360 & 105.8514 & $<0.0001$ \\
\hline BD & -4.8424 & 2220.4271 & 92.8614 & $<0.0001$ \\
\hline CD & 1.9611 & 270.6337 & 11.3183 & 0.0008 \\
\hline CF & 7.8064 & 308.4422 & 12.8995 & 0.0004 \\
\hline CDF & 9.5120 & 272.2222 & 11.3847 & 0.0008 \\
\hline Residual & - & 12672.9401 & - & - \\
\hline Cor Total & - & 52630.4007 & - & - \\
\hline \multicolumn{5}{|c|}{$\begin{array}{l}\text { A-Flash temperature; B-WFE Temperat } \\
\text { Pressure; E-SPE Level; F- WFE Level } \\
\text { Table 21: Model regression parameters }\end{array}$} \\
\hline $\begin{array}{c}\text { Model } \\
\text { Properties }\end{array}$ & $\begin{array}{c}\text { WFE Viscosity } \\
\text { Model }\end{array}$ & $\begin{array}{c}\text { SPE } \\
\text { Viscosity } \\
\text { Model } \\
\end{array}$ & $\begin{array}{l}\text { SPE Flow } \\
\text { Model }\end{array}$ & $\begin{array}{l}\text { WFE Flow } \\
\text { Model }\end{array}$ \\
\hline $\mathbf{R}^{2}$ & 0.9992 & 0.9586 & 0.9632 & 0.9992 \\
\hline Adj $R^{2}$ & 0.9992 & 0.9549 & 0.9596 & 0.9992 \\
\hline Pred $\mathbf{R}^{2}$ & 0.9992 & 0.9446 & 0.9478 & 0.9992 \\
\hline
\end{tabular}

Table 22: Confidence interval of optimised solution (Two-tailed t-test with $n=1)$

\begin{tabular}{ccccc}
\hline Response & $\begin{array}{c}\text { WFE } \\
\text { Viscosity } \\
\text { (cSt) }\end{array}$ & $\begin{array}{c}\text { SPE } \\
\text { Viscosity } \\
\text { (cSt) }\end{array}$ & $\begin{array}{c}\text { SPE } \\
\text { Flowrate } \\
\text { (LPM) }\end{array}$ & $\begin{array}{c}\text { WFE } \\
\text { Flowrate } \\
\text { (LPM) }\end{array}$ \\
\hline $\begin{array}{c}\text { Predicted } \\
\text { Mean }\end{array}$ & 10.0000 & 43.7527 & 28.2843 & 26.1653 \\
\hline Predicted & 10.0000 & 43.7527 & 28.2843 & 26.1653 \\
\hline
\end{tabular}




\begin{tabular}{ccccc}
\hline Median & & & & \\
\hline Std Dev & 0.0345 & 4.8899 & 3.9804 & 0.1533 \\
\hline n & 1 & 1 & 1 & 1 \\
\hline SE Pred & 0.0361 & 5.9735 & 5.9261 & 0.1899 \\
\hline $\mathbf{9 5 \%}$ PI low & 9.9290 & 32.0180 & 16.6424 & 25.7923 \\
\hline $\mathbf{9 5 \%}$ PI high & 10.0710 & 55.4874 & 39.9262 & 26.5384 \\
\hline
\end{tabular}

Table 23: Confirmation of optimisation results by sampling and error analysis

\begin{tabular}{ccccc}
\hline Properties & $\begin{array}{c}\text { WFE } \\
\text { Viscosity } \\
\text { (cSt) }\end{array}$ & $\begin{array}{c}\text { SPE } \\
\text { Viscosity } \\
\text { (cSt) }\end{array}$ & $\begin{array}{c}\text { SPE } \\
\text { Flowrate } \\
\text { (LPM) }\end{array}$ & $\begin{array}{c}\text { WFE } \\
\text { Flowrate } \\
\text { (LPM) }\end{array}$ \\
\hline $\begin{array}{c}\text { Optimised } \\
\text { Value }\end{array}$ & 10.00 & 43.75 & 28.28 & 26.16 \\
\hline Sample 1 & 10.19 & 44.71 & 28.25 & 26.31 \\
\hline Sample 2 & 10.29 & 43.92 & 28.39 & 26.33 \\
\hline Sample 3 & 10.04 & 44.39 & 28.34 & 26.67 \\
\hline Signal & 0.173333 & 0.59 & 0.046667 & 0.28 \\
\hline Pooled S.D. & 0.088976 & 0.28098 & 0.050166 & 0.14089 \\
\hline Noise & 0.072648 & 0.22942 & 0.040961 & 0.115036 \\
\hline $\begin{array}{c}\text { T-value } \\
\text { P value (Type } \\
\text { I Error) }\end{array}$ & 0.385924 & 2.571708 & 1.139304 & 2.434016 \\
\hline $\begin{array}{c}\text { P value (Type } \\
\text { II Error) }\end{array}$ & $<0.0001$ & 0.061867 & 0.318172 & 0.07167 \\
\hline & & & & \\
\hline
\end{tabular}




\section{References}

Abdi, H. and Williams, L. J. (2010). Principal Component Analysis. John Wiley \&Sons, Inc., 2, 433-459.

Aida, S., Matsuno, T., Hasegawa, T., Tsuji, K. (2017). Application of principal component analysis for improvement of X-ray fluorescence images obtained by polycapillary-based micro-XRF technique. Nuclear Instruments and Methods inPhysics Research B, 402, 267-273.

Al-Sayed, A. (2015). Principal component analysis within nuclear structure. Nuclear Physics A, 933, 154-164.

Alsayigh, A. (2015), Applying Lean Principles to Transform Conventional Oil \& Gas

Amminudin, K., Enezi, T., Jubran, M., Hajji, A.,Bedoukhi, Z. (2011). Gas plant improves C3 recovery with Lean Six Sigma approach. 19th Annual Technical Conference of the GCC Chapter of the Gas Processors Association.

Anderson, M. (2018). Design Expert Documentation. [online] Statease. Available at: https://www.statease.com/docs/v11/tutorials/combinedmix-process.html [Accessed 29 Oct. 2018].

Aspen Process Engineering Webinar (2006). Aspen HYSYS Property Packages Overview and Best Practices for Optimum Simulations. Aspentech, Galaxis, Singapore.

Atanas, J., Rodrigues, C., Simmons, R. (2016). Lean Six Sigma Applications in Oil and Gas Industry: Case Studies. International Journal of Scientific and Research Publications, 6(5), 540-544.

Bhattacharya, A., Jain, R., Choudhary, A. (2011). Green Manufacturing Energy, Products and Processes. The Boston Consulting Group, 1-24.

Box, G. E. P., Behnken, D. W. (1960). Some New Three Level Designs for the Study of Quantitative Variables. Technometrics, 2(4), 455-475.

Bratchell, N. (1989). Multivariate response surface modelling by principal components analysis. Journal of Chemometrics, 3(4), 579-588. 
Ning, C. and You, F. (2018). Data-driven decision making under uncertainty integrating robust optimization with principal component analysis and kernel smoothing methods. Computers and Chemical Engineering, Volume 112, 190-210.

Collins, L., Dziak, J., Li, R. (2009). Design of experiments with multiple independent variables: A resource management perspective on complete and reduced factorial designs. Psychological Methods, 14(3), 202-224.

Čuček, L., Klemeš, J.,Kravanja, Z. (2012). A Review of Footprint analysis tools for monitoring impacts on sustainability. Journal of Cleaner Production, 34, 9-20.

Chiang, L., Lu, B., Castillo, I. (2017). Big data analytics in chemical engineering. Annual review of chemical and biomolecular engineering, 8, 63-85.

Derringer, G. and Suich, R. (1980). Simultaneous Optimization of Several Response Variables.Journal of Quality Technology, 12(4), 214219.

Drovandi, C.C., Holmes, C., McGree, J.M., Mengersen, K., Richardson, S., Ryan, E.G. (2017). Principles of experimental design for Big Data analysis. Statistical science: a review journal of the Institute of Mathematical Statistics, 32(3), p.385.

Fisher, R. A. (1935). The Design of Experiments. Edinburg: Oliver \& Boyd. Gunst, R. F. and Mason, R. L. (2009). Fractional factorial design. WIRES CompStat, 1, 234-244.

Halvorsen, M., Elseth, G.,Naevdal, O. (2012). Increased oil production at Troll by autonomous inflow control with RCP valves. SPE Annual Technical Conference and Exhibition.

Hostelling, H. (1933). Analysis of a complex of statistical variables into principal components. Journal of Educational Psychology, 24(6), 417441.

How, B.S. and Lam, H.S. (2018a). Sustainability evaluation for biomass supply chain synthesis: Novel principal component analysis (PCA) aided optimisation approach. Journal of Cleaner Production, 189, 941-961.

How, B.S. and Lam, H.S. (2018b). PCA Method for Debottlenecking of Sustainability Performance in Integrated Biomass Supply Chain. (In Press) 
Process Integration and Optimization for Sustainability, doi.org/10.1007/s41660-018-0036-3.

Hu, Y., Li, G., Chen, H., Li, H., Liu, J. (2016). Sensitivity analysis for PCAbased chiller sensor fault detection. International Journal of Refrigeration, $63,133-143$.

Huda, L. and Matondang, R. (2018). The lean ergonomics in green design of crude palm oil plant. IOP Conference Series: Materials Science and Engineering, 309, 012109.

International Organization for Standardization (ISO) (2006). ISO 14044 :Environmental management - Life cycle assessment - Requirements and guidelines. 1st ed. Geneva: ISO.

Jackson, D. (1993). Stopping Rules in Principal Components Analysis: A Comparison of Heuristical and Statistical Approaches.Ecology, 74(8), pp.2204-2214.

Jolliffe, I. and Cadima, J. (2016). Principal component analysis: a review and recent developments. Philosophical Transactions of the Royal Society A: Mathematical, Physical and Engineering Sciences, 374(2065), 20150202.

Joly, M., Moro, L., Pinto, J. (2002). Planning and scheduling for petroleum refineries using mathematical programming. Brazilian Journal of Chemical Engineering, 19(2), 207-228.

Klemeš, J. and Kravanja, Z. (2013). Forty years of Heat Integration: Pinch Analysis (PA) and Mathematical Programming (MP). Current Opinion in Chemical Engineering, 2(4), 461-474.

Klemeš, J., Varbanov, P.,Huisingh, D. (2012). Recent cleaner production advances in process monitoring and optimisation. Journal of Cleaner Production, 34, 1-8.

Klemeš, J., Dhole, V., Raissi, K., Perry, S.,Puigjaner, L. (1997). Targeting and design methodology for reduction of fuel, power and CO2 on total sites. Applied Thermal Engineering, 17(8-10), 9931003.

Kraber, S. (2009). Response Surface Optimization. Stat-Ease Inc.

Krishna Madhavi, S., Sreeramulu, D., Venkatesh, M. (2017). Evaluation of Optimum Turning Process of Process Parameters Using DOE and PCA Taguchi Method. Materials Today: Proceedings, 4(2), 1937-1946. 
Lam, H., How, B. and Hong, B. (2015). Green supply chain toward sustainable industry development. Assessing and Measuring Environmental Impact and Sustainability, 409-449.

Leong. W.D., Lam. H.L., Ng. W.P.Q., Lim. C.H., Tan. C.P., Ponnabalam. S.G., (2018), Lean and Green Manufacturing - A Review on Application and Effect. Process Integration and Optimization for Sustainability. (In Press)

Mckay, B., Willis, M., Barton, G. (1997). Steady-state modelling of chemical process systems using genetic programming. Computers \& Chemical Engineering, 21(9), 981-996.

Morita, T., Yogo, S., Koike, M., Hamaguchi, T., Jung, S., Koshijima, I., Hashimoto, Y., (2013). Detection of cyber-attacks with zone dividing and PCA. Procedia Computer Science, 22, 727-736.

Murray, P. and Forfar, L. (2017). The Application of Advanced Design of Experiments for the Efficient Development of Chemical Processes. Chemical Informatics, 03(02).

Nobi, A., Alam, S., Lee, J.W., (2017). Dynamic of consumer groups and response of commodity markets by principal component analysis. Physica A: Statistical Mechanics and its Applications, 482, 337-344.

Pearson, K. (1901). On lines and planes of closest fit to systems of points in space. Philosophical Magazine,2,559-572. http://pbil.univlyon1.fr/R/pearson1901.pdf

Porter, M. E. and Linde, V. D. (1995). Green and competitive:

Ending the stalemate. Harvard Bus. Rev., 73(5), 120-134.

Production Operations in a Gulf State into Cleaner Energy, PhD Thesis, Loughborough University, England.

Rea, A. and Rea, W., (2016). How Many Components should be Retained from a Multivariate Time Series PCA? arXiv preprint arXiv:1610.03588.

Schneider, D. F. (1997). Debottlenecking Options and Optimization, Houston: Stratus Engineering, Inc.

Shlens, J. (2014). A Tutorial on Principal Component Analysis. eprintarXiv:1404.1100. 
Smith, R. and Linnhoff, B. (1988). Design of separators in the context of overall processes. Chemical Engineering Research and Design, 66(3), 195-228.

Telford, J. K. (2007). A brief introduction to design of experiments. JohnsHopkins APL Technical Digest (Applied Physics Laboratory), 27(3), 224-232.

The Carbon Trust (2011). Energy and Carbon conversion factors, London: The Carbon Trust.

Toyota, H., Asai, T. and Oku, N. (2017). Process optimization by use of design of experiments: Application for liposomalization of FK506. European Journal of pharmaceutical Sciences, 102, 196-202.

Wan Alwi, S.R., Abdul Manan, Z., Klemeš, J.J., Huisingh, D., (2014). Sustainability engineering for the future. Journal of Cleaner Production, 71, 1-10.

Wang, X., Jiang, D. and Lang, X. (2017). Future extreme climate changes linked to global warming intensity. Science Bulletin, 62(24), 1673-1680.

WBCSD Chemicals (2013). Life Cycle Metrics for Chemical Products: A guideline by the chemical sector to assess and report on the environmental footprint of products, based on life cycle assessment, Washington: WBCSD Chemicals.

WCED (1987). The Brundtland Report: 'Our common future', Oxford: Oxford University Press.

Zhang, Y. and Edgar, T. (2008). PCA Combined Model-Based Design of Experiments (DOE) Criteria for Differential and Algebraic System Parameter Estimation. Industrial \& Engineering Chemistry Research, 47(20), 7772-7783. 
Highlights

1. PCA is used to select statistical significant variables in plant-wide optimization.

2. Compared to conventional method, the framework can reduce risks and capital cost.

3. The framework is applied in a real case study in a waste oil re-refining plant.

4. The overall product improved $55.25 \%$ by yield and $20.6 \%$ by quality.

5. Global Warming and Acidification Potential reduced by $3.42 \%$ and $90.89 \%$ respectively. 